\title{
A Meta-analysis on the Effect of Kangaroo Mother Care on Preterm Mortality
}

\author{
Maria Esterlita T. Villanueva-Uy, MD, MSPH, 1,2,6 Michael Q. Van Haute, MD,3,4,5 \\ Erena S. Kasahara, MD² and Socorro De Leon-Mendoza, MD $^{6}$ \\ ${ }^{1}$ Institute of Child Health and Human Development, National Institutes of Health, University of the Philippines Manila \\ ${ }^{2}$ Division of Newborn Medicine, Department of Pediatrics, Philippine General Hospital, University of the Philippines Manila \\ ${ }^{3}$ Department of Epidemiology and Biostatistics, College of Public Health, University of the Philippines Manila \\ ${ }^{4}$ De La Salle Medical and Health Sciences Institute, College of Medicine, Dasmariñas City, Cavite \\ ${ }^{5}$ San Beda University College of Medicine, Mendiola, Manila \\ ${ }^{6}$ Kangaroo Mother Care Foundation Philippines, Inc.
}

\begin{abstract}
Background. Kangaroo mother care $(\mathrm{KMC})$ is a low-cost but high-impact intervention for preterm and low birth weight (LBW) infants.

Objectives. To determine the effect of KMC on in-hospital mortality among preterm and LBW infants, taking into consideration their gestational age, birth weight, income category of the country of birth, and medical stability.

Materials and Methods. A comprehensive search of several databases, as well as local listings of research papers, was performed to look for randomized controlled studies with KMC as intervention, and mortality and length of hospitalization as outcome measures. The risk of bias and publication bias was assessed. We did subgroup analyses based on income category of the country of birth, gestational age, birth weight, and medical stability of the infants.
\end{abstract}

Results. Sixteen randomized controlled trials (RCTs) with 1738 infants in the KMC group and 1674 infants in the control group were included. Based on the GRADE approach, although all the studies were RCTs, the evidence is assessed as moderate certainty due to the nature of the intervention (KMC) that prevented blinding. There was a $41 \%$ reduction in risk of dying among preterm and low birth weight infants who received KMC compared to conventional medical care (3.86\% vs $6.87 \%$; $\mathrm{RR}=0.59,95 \% \mathrm{Cl} 0.44,0.79 ; \mathrm{I}^{2}=0 \%$; number needed to treat for additional benefit $(\mathrm{NNTB})=34 ; 16 \mathrm{RCTs} ; 3,412$ infants). Furthermore, there were also reductions in the risk of dying among infants who were <34 weeks AOG (KMC: $4.32 \%$ vs CMC: $8.17 \%, \mathrm{RR}=0.55,95 \% \mathrm{Cl} 0.38,0.79 ; \mathrm{I}^{2}=$ $0 \%$; NNTB $=26 ; 10$ RCTs; 1795 infants), with birthweight of $>1500$ g (KMC: $3.97 \%$ vs CMC: $6.83 \%$, RR $=0.60 ; 95 \%$ $\mathrm{Cl} 0.45,0.82 ; \mathrm{I}^{2}=0 \%$; NNTB = 35; 10 RCTs; 2960 infants), and born in low- and middle income countries (LMIC) (3.77\% vs 6.95\%; RR = 0.57, 95\% Cl 0.43, 0.77; $I^{2}=0 \%$; NNTB = 32; 14 RCTs; 3281 infants). There was a significant reduction in mortality (KMC: $11.05 \%$ vs CMC: $20.94 \%$; RR = 0.54; $95 \% \mathrm{Cl} 0.34,0.87 ; \mathrm{I}^{2}=0 \%$; NNTB = 11; 5 RCTs; 387 infants) even among medically unstable infants who received KMC compared to those who did not. The length of hospitalization did not significantly differ between the KMC and the control groups. Due to high heterogeneity, subgroup analyses were performed, which showed a trend towards a shorter length of hospital stay among preterm infants $<34$ weeks AOG, with birthweight $\geq 1500 \mathrm{~g}$, medically unstable during admission, and belonging to LMIC but did not reach statistical significance.

Conclusion. There was moderate certainty evidence that KMC can decrease mortality among preterm and LBW infants. Furthermore, KMC was beneficial among relatively more premature, bigger, medically unstable preterm infants and born in low to middle-income countries.

Key Words: kangaroo mother care, preterm, low birth weight, mortality, hospital stay

Corresponding author: Maria Esterlita T. Villanueva-Uy, MD, MSPH

Institute of Child Health and Human Development

National Institutes of Health, University of the Philippines Manila

623 Pedro Gil Street, Ermita, Manila 1000, Philippines

Email: mvuy1@up.edu.ph 


\section{INTRODUCTION}

\section{Description of the condition}

The first month of the life of a newborn is considered the toughest period for childhood survival. In 2019, the global average neonatal mortality rate (NMR) is 17 deaths per 1,000 live births. Although there has been a significant reduction in neonatal mortality rate (NMR) from 38 deaths per 1000 live births in 1990, NMR remains a major contributor to childhood mortality. ${ }^{1}$ Neonatal death comprises $47 \%$ of under-5 childhood mortality. Of these deaths, 99\% occur in low to middle-income countries and most of these are considered preventable deaths. ${ }^{2}$ In 2019 , $1 / 3$ of newborns died in the first 24 hours of life and 3/4 died within the first week. ${ }^{3}$ Neonates predominantly die of complications of preterm births (35\%), intrapartum events (24\%), infections (15\%), and congenital anomalies (11\%). ${ }^{4}$

WHO initiatives, such as $A$ Promise Renewed and Every Nerwborn Action Plan, set specific targets also reflected in the Sustainable Development Goals (SDGs) that aim to end preventable deaths of newborn babies and children younger than 5 years by 2030 . SDG 3.2 stipulates that all countries shall aim to reduce neonatal mortality to 12 deaths per 1000 live births or fewer. ${ }^{5}$

Although substantial progress has been made in reducing neonatal mortality over the past years, there is still a need to accelerate all efforts in the next 5 years to achieve the SDG target by 2030. Faster improvements are much desired in the regions with high NMR, especially in sub-Saharan Africa and South Asia. ${ }^{5}$

\section{Description of the intervention}

Kangaroo Mother Care (KMC) started in the 1970s in Bogota, Colombia, and has been considered as an innovative and daring intervention to care for low-birthweight (LBW) infants. ${ }^{6}$

In 2015, the World Health Organization (WHO) has recommended that $\mathrm{KMC}$ should be routine care for newborn infants weighing $2000 \mathrm{~g}$ or less and initiated once the infants are clinically stable. ${ }^{7}$ Aside from assurance of thermoregulation among the lower birth weight or preterm infants, KMC has been proven to significantly improve preterm survival. The meta-analysis of Aguedo-Conde in 2016 showed a reduction in the risk of dying by $40 \%$ among infants who received $\mathrm{KMC}$. An apparent dose-response relationship was likewise observed with $\mathrm{KMC}$, wherein earlier initiation and a longer duration rendered led to a greater reduction in mortality. ${ }^{8}$

$\mathrm{KMC}$ is comprised of prolonged skin-to-skin contact between the baby and the mother, exclusive breastmilk feeding, and early discharge. ${ }^{7}$ However, in a recent review of publications, there seem to be variable definitions of the $\mathrm{KMC}$ intervention with $71 \%$ defining $\mathrm{KMC}$ in terms of skin-to-skin contact only. Only a few publications included the other integral components of the KMC intervention, namely exclusive breastfeeding (16\%), early discharge (7\%), and follow-up (12\%). ${ }^{9}$ In this review, the skin-to-skin component of the KMC intervention is considered.

\section{How the intervention might work}

The reasons for the significant reduction in mortality among preterm or LBW infants who received $\mathrm{KMC}$ are multifactorial. Foremost, KMC has been shown to ensure better thermoregulation among these high-risk infants. In a small randomized controlled trial (RCT) comparing KMC and conventional care (infant inside an incubator), there was more than a $90 \%$ reduction in hypothermia among infants $<2000 \mathrm{~g}$ birth weight. ${ }^{10}$ Hypothermia is recognized to be associated with higher morbidities such as arrhythmia, bleeding, thrombosis, intraventricular hemorrhage, and sepsis. ${ }^{11}$

In a small randomized study of 52 very preterm infants randomized to $\mathrm{KMC}<3$ hours/day versus $\mathrm{KMC} \geq 3$ hours/ day, there was a significantly lower incidence of nosocomial sepsis among those provided longer KMC sessions. Other preterm complications like bronchopulmonary dysplasia, intraventricular hemorrhage, necrotizing enterocolitis, and growth parameters were the same between the two groups. The reduction in sepsis rates was hypothesized to be due to the higher frequency of infants breastfed in the KMC group compared to the control. ${ }^{12}$ A meta-analysis in 2019 concurred and showed higher breastfeeding rates among KMC mothers. ${ }^{13}$ Likewise, in another meta-analysis, KMC mothers were able to initiate breastfeeding earlier than the non-KMC mothers. ${ }^{14}$ Breastmilk has been shown to not only contain optimal nutrition but also bioactive reagents that are known to fight infections. Exclusive breastfeeding, as mentioned earlier, is an integral part of the KMC intervention.

In a randomized trial, infants have better physiologic parameters (heart rate, respiratory rate, and oxygen saturation) while on KMC compared with baseline (pre-KMC session) and compared with infants on conventional care. ${ }^{15}$ This may indicate a calmer preterm infant. This may have led to faster growth velocities observed among KMC infants. ${ }^{16}$ In another randomized controlled trial, infants randomized to $\mathrm{KMC}$ have lower levels of the stress hormone, cortisol, in their saliva at 1 month. Furthermore, even the mothers' salivary cortisol levels correlated with those of their infants at 4 months, which may also indicate a more relaxed mother. The fathers of KMC mother-infant dyads also seem to be in a more comfortable relationship with their wives as they scored lower in the questionnaire on spouse relationship problems. ${ }^{17}$ It seems that there is less stress not only among the preterm infants on $\mathrm{KMC}$ but also among their mothers and their family in general.

There is a more rapid improvement among KMC infants on respiratory support. In a retrospective cohort of 145 extremely LBW infants, the duration of non-invasive ventilation and oxygen support were significantly shorter among infants provided with KMC. Similarly, episodes of 
apnea were also less among the preterm infants on KMC. All these may lead to a short hospital stay. ${ }^{18}$

Aside from increased survival, $\mathrm{KMC}$ infants were found to fare better in terms of neurobehavioral performance. In a RCT, preterm infants in the KMC group scored higher for attention, quality of movements, and lower scores on asymmetry and signs of stress and abstinence while in the hospital. ${ }^{19}$ Aside from having better short-term outcomes among the KMC infants, a 20-year follow up of these infants showed that they were more employable, more socially adaptable, and had more stable homes compared with those who were not provided KMC. ${ }^{20}$

\section{Why it is important to do this review?}

$\mathrm{KMC}$ is a cost-effective and efficacious intervention in preventing preterm mortality in in-hospital deliveries. ${ }^{21}$ Despite the robust evidence of multiple benefits of $\mathrm{KMC}$ to both the mothers and the babies, the number of hours $\mathrm{KMC}$ rendered is usually only from 3-5 hours/day, which is much less than the recommended for intermittent $\mathrm{KMC}$ ( $\geq 8$ hours/day) and continuous KMC ( $\geq 20$ hours/day). ${ }^{22}$ Furthermore, the quality of $\mathrm{KMC}$ implementation in developing countries is poor, with only $59.0 \%$ of the facilities ready to provide $\mathrm{KMC}$ service and only $46 \%$ of the eligible infants receiving $\mathrm{KMC} .{ }^{23}$

Several factors influence the uptake of KMC, which include context-specific interventions such as the development of guidelines, behavior change materials, training curriculum, and job aids. Societal and cultural norms are also taken into consideration. The barriers identified have been the perception that $\mathrm{KMC}$ is not based on scientific fact, the inconsistent application of KMC within the facilities, the lack of leadership and support from management, and the perception of non-priority of newborn care in the health system. There is also the perception that KMC is only safe for stable LBW infants. ${ }^{24}$

In a meta-analysis by Boundy (2016), pooled estimates from 24 studies showed a $36 \%$ reduction in mortality (RR 0.64; 95 CI 0.46, 0.89), a 47\% lower risk of neonatal sepsis (RR 0.53; 95\% CI 0.34, 0.83), a 78\% reduction in hypothermia (RR $0.22 ; 95 \%$ CI $0.12,0.41$ ), a $92 \%$ reduction in hypoglycemia (RR 0.12; 95\% CI 0.05, 0.32), and a 1.5 -fold increase in the chance of exclusive breastfeeding (RR 1.50; 95\% CI 1.26, 1.78). However, there have been no further analyses using states of medical stability and geographical regions as subgroups. ${ }^{25}$

An updated meta-analysis of 21 studies by CondeAgudelo (2016) showed a 40\% reduction in the risk of dying, a $65 \%$ reduction in the risk of sepsis, and a $72 \%$ reduction in the risk of hypothermia. The weight, length, and head circumference increment rates are faster among the $\mathrm{KMC}$ group. However, only one study on KMC provided to infants before stabilization has been analyzed and has not shown any significant reduction in mortality. No subgroup analyses on the gestational age and birthweight were done. ${ }^{8}$
Although the 2015 recommendation of $\mathrm{WHO}^{7}$ is to provide $\mathrm{KMC}$ as part of neonatal care for clinically stable infants, in recent years, KMC has been provided even in unstable preterm or LBW infants. A mixed-method study by Morgan on the feasibility and acceptability of KMC provided to unstable infants $<2000$ grams has shown that $75 \%$ of the mothers agreed that KMC may be provided to medically unstable infants. Clinical instability among infants is defined as receiving $\geq 2$ medical therapies. ${ }^{26}$

Providing evidence of the benefits of KMC among preterm and LBW infants may further influence clinicians and policymakers in improving $\mathrm{KMC}$ implementations in both stable and unstable infants.

\section{SIGNIFICANCE}

The implementation of KMC programs has faced challenges over the years. Providing additional information on its benefits on preterm mortality and hospital cost may further motivate stakeholders in the acceptance of the KMC programs.

\section{OBJECTIVE}

To determine if KMC provided among preterm or LBW infants will decrease in-hospital neonatal mortality and length of hospital stay.

\section{MATERIALS AND METHODS}

\section{Criteria for considering studies for this review}

\section{Types of studies}

Only randomized controlled single-blind studies were eligible for inclusion in this review. Studies that were not intention-to-treat or permitted cross-over to other study groups were also not included. There were no restrictions imposed in terms of language and publication status. Google Translate was used for foreign-language publications.

\section{Types of participants}

This review included only studies that involve preterm infants $(<37$ completed weeks) or LBW infants $(<2,500 \mathrm{~g}$ birth weight).

\section{Types of interventions}

Only studies with interventions stated as $\mathrm{KMC}$, kangaroo mother care, or skin-to-skin contact, started only during the hospital stay, were included in this review. Studies in which KMC was in combination with other interventions, or was started post-discharge or in the community were not included. Control group infants were those who received conventional care such as placement inside an incubator, a radiant warmer, or a bassinet. Traditional holding was also considered an acceptable control intervention. 


\section{Types of outcome measures}

The primary outcome of interest was in-hospital mortality. A secondary outcome variable was the length of hospitalization. These outcome measures would reflect the effectiveness of $\mathrm{KMC}$ in reducing deaths (mortality) as well as in facilitating faster improvement from preterm complications (length of hospitalization). Studies, where outcome variables did not include mortality, were not included in the review.

\section{Search methods used to identify the studies}

\section{Electronic searches}

The following databases were searched thoroughly: Cochrane Central Register of Controlled Trials (CENTRAL), U.S. National Library of Medicine via PubMed, Scopus, LILACS (Latin American and Caribbean Health Sciences Literature), Embase (Excerpta Medica Database), and CINAHL (Cumulative Index to Nursing and Allied Health Literature). The Cochrane Database of Systematic Reviews was also searched for reviews or metaanalyses. The WHO International Clinical Trials Registry Platform and ClinicalTrials.gov were also searched for ongoing clinical trials. The authors also searched for local studies from the Health Research and Development Information Network (HERDIN), Philippine Index Medicus, and the Philippine Journal of Pediatrics. There were no restrictions imposed on language or year of publication. The last update was performed in September 2020. The search strategy for "CENTRAL" and "MEDLINE" used the $\mathrm{MeSH}$ terms 'kangaroo mother care', 'skin to skin contact', 'low birth weight', and 'preterm neonates' and 'randomized controlled trials.'

\section{Searching other resources}

The citation list of eligible trials was explored to find other studies. The Philippine General Hospital Department of Pediatrics Research Inventory from 2011 to 2018 was likewise searched for published and unpublished studies. Inquiry into the list of submitted research studies (published and unpublished) to the Philippine Society of Newborn Medicine, as well as studies funded by the Kangaroo Mother Care Foundation Philippines, were also done. Some authors were contacted by e-mail regarding the possible eligibility of their studies for this review.

\section{Data collection and analysis}

We utilized the standard methods of the Cochrane Neonatal Review Group and The Cochrane Collaboration.

\section{Selection of studies}

Only randomized controlled trials that fulfilled set criteria and included hospital mortality were reviewed. Duplicate publications were removed.

\section{Data extraction and management}

Two authors independently extracted and assessed the accuracy of data from the clinical trials. Disparities between the two authors were resolved by discussion among the authors. Data input was through the Review Manager Version 5.3 (RevMan) software.

\section{Assessment of risk of bias in included studies}

Two authors independently assessed the risk of bias of all included trials as outlined in the Cochrane Handbook for Systematic Reviews of Intervention. ${ }^{27}$ Assessments were specified as 'low risk,' 'high risk,' or 'unclear.' Any disparity was resolved by discussion among the authors.

\section{Sequence generation}

Selection bias was assessed as a) Low risk - application of randomization such as random number via a table or computer-generated; b) High risk - any non-random process, e.g., hospital number; or c) Unclear.

\section{Allocation concealment}

The allocation concealment methods were assessed as a) Low risk - telephone or central randomization, consecutively numbered-sealed envelopes, coding by the third party; b) High risk - unsealed or non-opaque envelopes, alternation; or c) Unclear.

\section{Blinding}

The methods for blinding affect performance and detection bias. Trials were assessed as low risk if the process of blinding was defined in the included trials. Otherwise, the trials were assessed as either high risk (no blinding) or unclear. The blinding assessment included both the research personnel and the outcome assessor.

\section{Incomplete outcome data}

The completeness of data was assessed based on the number of participants included in the analysis compared with the total randomized participants to check for possible attrition bias. The methods were assessed as a) Low risk (<20\% missing data); b) High risk ( $\geq 20 \%$ missing data); or c) Unclear.

\section{Selective reporting bias}

This bias was assessed as a) Low risk - if the study reported all pre-specified outcomes and all expected outcomes of interest, b) High risk - if not all of the study's pre-specified outcomes were reported, outcomes of interest were incompletely reported and thus could not be used, or non-inclusion of the results of an important outcome expected to have been reported; or c) Unclear.

\section{Other sources of bias}

The included studies were assessed for other sources of bias such as imbalances in baseline data, possible reports 
of fraudulence, issues with sample size, and the presence of conflicts of interest. As with the other biases listed under the Cochrane Handbook for Systematic Reviews of Intervention, these other biases will be judged as 'low risk' (no evidence of such biases), 'high risk' (clear evidence of such biases), or 'unclear' (insufficient data to assess bias).

\section{Overall risk of bias}

The authors assessed the trials based on the criteria given in the Cochrane Handbook for Systematic Reviews of Interventions. The direction and magnitude of the bias, and whether it was likely to impact the results were assessed.

\section{Measures of treatment effect}

The statistical analyses were based on the standard methods of the Cochrane Neonatal Review Group. Continuous data were analyzed using mean differences (MD) while dichotomous data were reflected on summary risk ratios (RR). All the point estimates were reported together with the 95\% confidence intervals (CI). The number needed to treat (or harm) was also calculated.

\section{Unit of analysis issues}

Included studies were randomized controlled trials, with the unit of analysis being preterm or LBW infants admitted in the hospital.

\section{Assessment of heterogeneity}

To be able to assess the appropriateness of pooling data, heterogeneity between studies was evaluated using the I-squared $\left(\mathrm{I}^{2}\right)$ statistic. The degree of heterogeneity was categorized based on the following ranges as suggested by Higgins et al. ${ }^{27}:<25 \%=$ none, $25-49 \%=$ low, $50-74 \%=$ moderate, $>75 \%=$ high .

\section{Assessment of reporting bias}

A search for unpublished studies was conducted in the following trial registries: ClinicalTrials.gov $(n=7)$, ISRCTN (International Standard Randomized Controlled Trial Number) ( $\mathrm{n}=7$ ), and ICTRP (International Clinical Trials Registry Platform of the World Health Organization) $(n=137)$. A similar search was likewise conducted among the list of local Neonatology Fellowship unpublished research papers. Outcome estimates from all included studies (published and unpublished) were encoded in the Review Manager software (RevMan version 5.3) and the appropriate funnel plot was generated and inspected for symmetry.

\section{Data synthesis}

Statistical analysis was performed using RevMan version 5.3. Outcomes were analyzed on an intention-to-treat basis. The random-effects model was used to pool the data for meta-analysis. The Mantel-Haenszel method was used for approximations of risk ratios for categorical outcomes (inhospital mortality). For continuous outcomes (length of hospital stay), the inverse variance method was employed to determine the pooled mean difference. A p-value of $<0.05$ was considered statistically significant.

\section{Quality of Evidence}

The Grading of Recommendations, Assessment, Development and Evaluation (GRADE) approach, as outlined in the GRADE Handbook ${ }^{28}$ was used to assess the quality of evidence contained within the included studies. Results of randomized trials are considered high-quality evidence by default. For some of the included studies, however, downgrading by one to two levels has occurred after considering the following: publication bias, risk of bias, directness of evidence, and consistency across the studies.

\section{Subgroup analysis and investigation of hetero- geneity}

For the primary outcome of in-hospital mortality, analyses were performed on the following pre-specified subgroups: economic status of the country of birth (high income vs low-to-middle income), gestational age $(<34$ weeks vs $\geq 34$ weeks), birth weight ( $<1500 \mathrm{~g}$ vs $\geq 1500 \mathrm{~g}$ ) and medical stability (unstable vs stable). Medical instability was defined as infants requiring respiratory support (oxygen, CPAP [continuous positive airway pressure], HFNC [high-flow nasal cannula], NIPPV [non-invasive positive pressure ventilation] and IPPV [invasive positive pressure ventilation]).

\section{Sensitivity analysis}

In the event of moderate to high heterogeneity, we planned to do sensitivity analysis by excluding the following studies that may be deemed problematic: studies with inadequate randomization; studies with unclear or disputed concealment of allocation; or studies with significant loss to follow up.

\section{RESULTS}

\section{Results of the search}

There were 1,207 records obtained using the following search strategy: MeSH words ["kangaroo mother care" OR "skin to skin"] AND ["preterm infants" OR "low birth weight"] AND "randomized controlled trial." Databases searched were PubMed ${ }^{\circledR}$, Embase (Excerpta Medica Database), LILACS (Latin American and Caribbean Health Sciences Literature), CINAHL (Cumulative Index to Nursing and Allied Health Literature), SCOPUS, ClinicalTrials. gov. and the local database, HERDIN (Health Research and Development Information Database). Three studies were obtained from the Philippine Society of Newborn Medicine list of researches submitted by Neonatology Fellowship graduates as part of their requirements for board eligibility. Only 519 studies were screened after removing duplicates. There were 116 studies that were assessed for 
eligibility. Excluded studies mostly did not include or report mortality as the outcome variable. Most RCTs were on the effect of KMC on pain. Studies with interventions of KMC plus another intervention (touch therapy, music, early family intervention, sucrose, breastfeeding) were not included. Studies where skin-to-skin contact was not a daily intervention for some time, but rather just one session during resuscitation, were not included. Comparison studies of early and late $\mathrm{KMC}$ were also not considered. Ultimately, only $16 \mathrm{RCT}$ s were included in the review (Figure 1).

\section{Description of included studies}

There were 15 single center RCTs and 1 multicenter RCT involving Ethiopia, Mexico and Indonesia. There were 1738 infants who were randomized to the KMC group and 1674 infants to the conventional medical care (CMC) group.

With regards to the subgroups on the economic status of the country of birth, two RCTs were from high-income countries, namely, UK (Whitelaw) and USA (Rojas), while the remaining $14 \mathrm{RCT}$ s were from the following

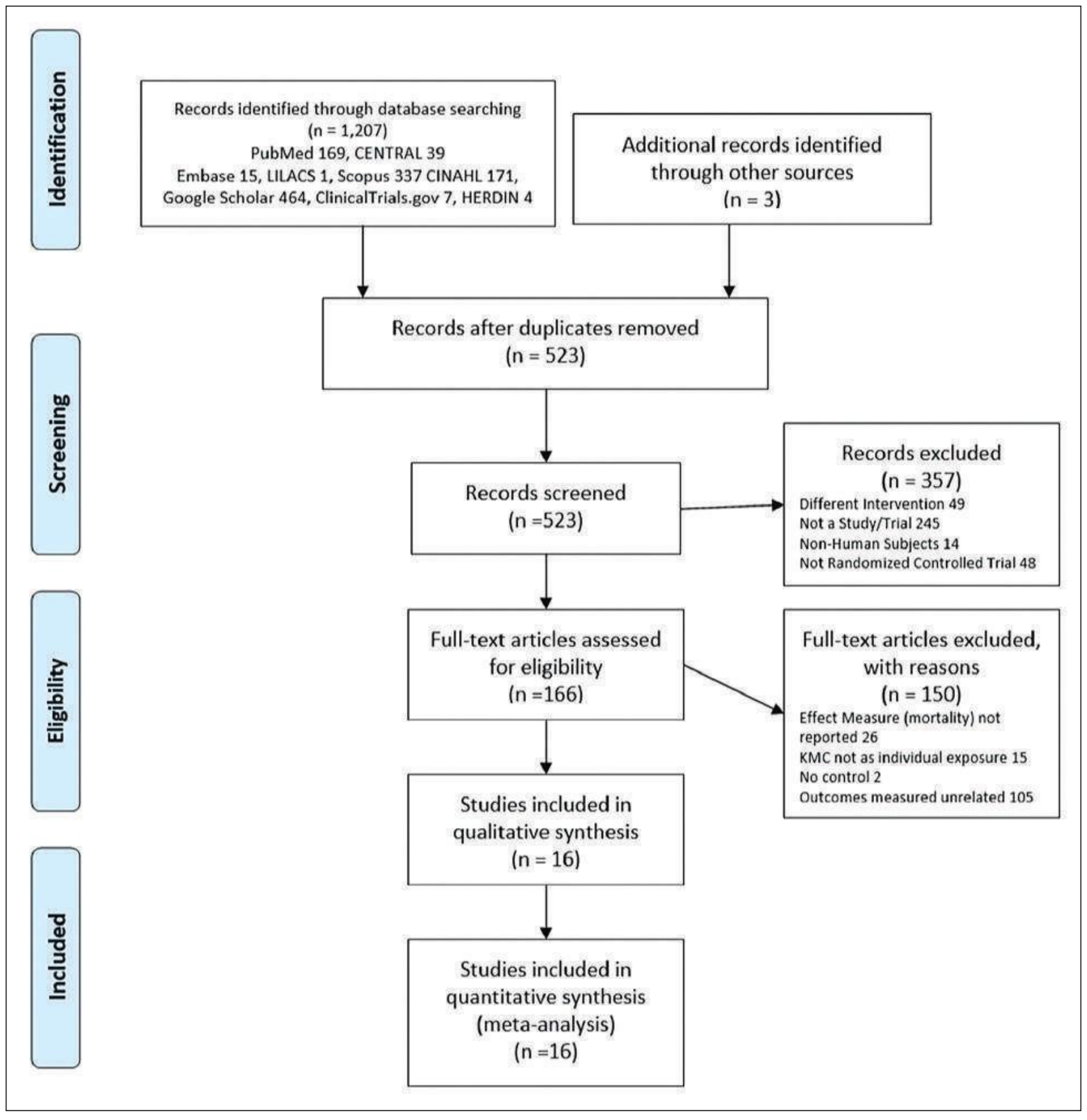

Figure 1. Study flow diagram. 
low-to-middle income countries: India (Kadam; Rao), Ethiopia (Cattaneo; Worku), Mexico (Cattaneo), Indonesia (Cattaneo), Kenya (Mwendwa), Ecuador (Sloan), Colombia (Charpak [1997]; Charpak [2001]; Tessier), Nepal (Acharya), Philippines (Baton; Fortifaes; Luistro) and Zimbabwe (Kambarami). For the subgroups of gestational age at birth, $2 \mathrm{RCT}$ s recruited infants with AOG $\geq 34$ weeks (Rao; Sloan), while $14 \mathrm{RCT}$ s recruited infants with AOG <34 weeks (Acharya; Baton; Cattaneo; Charpak [1997]; Charpak

Table 1. Summary of characteristics of the included studies

\begin{tabular}{|c|c|}
\hline Characteristics of included studies & $N=16$ \\
\hline \multicolumn{2}{|l|}{ Year of publication } \\
\hline$<1990$ & 1 \\
\hline 1990-1999 & 4 \\
\hline $2000-2009$ & 6 \\
\hline $2010+$ & 6 \\
\hline \multicolumn{2}{|l|}{ Sample size } \\
\hline$<50$ & 1 \\
\hline $50-99$ & 4 \\
\hline $100-199$ & 4 \\
\hline $200-299$ & 2 \\
\hline $300-399$ & 3 \\
\hline $400+$ & 2 \\
\hline \multicolumn{2}{|l|}{ Study site } \\
\hline Single & 1 \\
\hline Multiple & 3 \\
\hline \multicolumn{2}{|l|}{ Country } \\
\hline Colombia & 3 \\
\hline Ecuador & 1 \\
\hline Ethiopia & $2^{*}$ \\
\hline Kenya & 1 \\
\hline Indonesia & $1^{*}$ \\
\hline India & 2 \\
\hline Mexico & $1^{*}$ \\
\hline Nepal & 1 \\
\hline Philippines & 3 \\
\hline United Kingdom & 1 \\
\hline United States & 1 \\
\hline \multicolumn{2}{|l|}{ Medical Stability } \\
\hline Stable & 11 \\
\hline Unstable & 5 \\
\hline \multicolumn{2}{|l|}{ Duration of KMC/day (hours) } \\
\hline$<3$ & 2 \\
\hline $3-6$ & 3 \\
\hline $6-12$ & 3 \\
\hline $12-18$ & 1 \\
\hline$>18$ & 6 \\
\hline Not stated & 1 \\
\hline
\end{tabular}

*Countries included in the multi-country study of Cattaneo 1998.
[2001]; Fortifaes; Kadam; Luistro; Mwendwa; Rojas; Tessier; Whitelaw; Worku). Ten RCTs recruited infants with birthweights <1500 g (Acharya; Baton; Kadam; Kambarami; Luistro; Mwendwa; Rojas; Tessier; Whitelaw; Worku) while 6 RCTs recruited infants who weight $\geq 1500 \mathrm{~g}$ at birth (Cattaneo; Charpak [1997]; Charpak [2001]; Fortifaes; Rao; Sloan). Five RCTs enrolled medically unstable infants (Baton; Fortifaes; Luistro; Rojas; Worku). A summary of the study characteristics and a detailed description of the included studies are provided in Tables 1 and 2 .

\section{Risk of bias assessment of the included studies (Figure 2)}

\section{Allocation (selection bias)}

Four RCTs allocated their infants randomly to either $\mathrm{KMC}$ or control groups using random number tables

\begin{tabular}{|c|c|c|c|c|c|c|c|}
\hline & 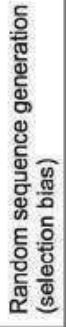 & 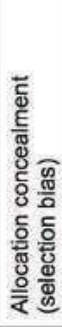 & 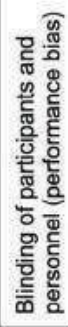 & 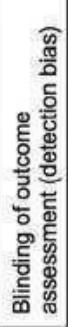 & 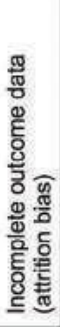 & 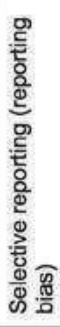 & 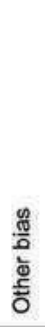 \\
\hline Acharya (2014) & 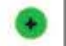 & 4 & $\odot$ & $?$ & $\odot$ & + & $?$ \\
\hline Baton (2017) & 4 & 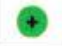 & $\odot$ & $?$ & $\odot$ & + & + \\
\hline Cattaneo (1998) & $\odot$ & 4 & ○ & $?$ & 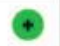 & $\odot$ & $?$ \\
\hline Charpak (1997) & 4 & 4 & $\odot$ & $\ominus$ & + & + & + \\
\hline Charpak (2001) & + & $\oplus$ & $\ominus$ & $\Theta$ & + & 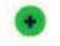 & $?$ \\
\hline Fortifaes (2017) & $\odot$ & 4 & C & $?$ & 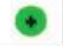 & 4 & 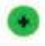 \\
\hline Kadam (2005) & $\odot$ & 4 & $\odot$ & $?$ & + & 4 & $?$ \\
\hline Kambarami (1998) & $\odot$ & $\odot$ & $\odot$ & $?$ & + & 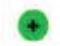 & $?$ \\
\hline Luistro (2014) & $\odot$ & $\odot$ & e & $?$ & $\odot$ & $\odot$ & $?$ \\
\hline Mwendwa (2012) & $\odot$ & $?$ & $\ominus$ & $?$ & $\odot$ & 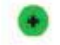 & $?$ \\
\hline Rao (2008) & 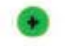 & $\oplus$ & $\odot$ & $?$ & $\ominus$ & 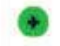 & $?$ \\
\hline Rojas (2003) & $\oplus$ & 4 & $\odot$ & $?$ & $\oplus$ & $\odot$ & $?$ \\
\hline Sloan (1994) & 4 & 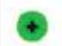 & ค & $?$ & 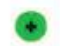 & $\hookrightarrow$ & $?$ \\
\hline Tessier (2003) & (4) & 4 & . & $?$ & ○ & 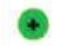 & $?$ \\
\hline Whitelaw (1988) & $\oplus$ & 4 & & $\ominus$ & + & $\odot$ & $\hookrightarrow$ \\
\hline Worku (2005) & $\odot$ & 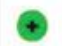 & ○ & ○ & $?$ & $\odot$ & $?$ \\
\hline
\end{tabular}

Figure 2. Risk of bias summary. 
Table 2. Characteristics of Included Studies Comparing KMC and Conventional Care on Premature, LBW Infants

\begin{tabular}{|c|c|c|c|c|}
\hline $\begin{array}{l}\text { Study, Year, } \\
\text { and Design (n) }\end{array}$ & $\begin{array}{c}\text { Inclusion and } \\
\text { Exclusion Criteria }\end{array}$ & Study Groups & $\begin{array}{l}\text { Description of Infants } \\
\text { Included in the Study }\end{array}$ & $\begin{array}{l}\text { Outcomes } \\
\text { Measured }\end{array}$ \\
\hline $\begin{array}{l}\text { Acharya, } \\
2014 \\
\text { Single-center } \\
\text { RCT } \\
(n=126)\end{array}$ & $\begin{array}{l}\text { Inclusion: Neonates with birth } \\
\text { weight <2000 g. } \\
\text { Exclusion: Critically ill infants } \\
\text { requiring ventilatory or } \\
\text { inotropic support or radiant } \\
\text { warmer; chromosomal and } \\
\text { life-threatening congenital } \\
\text { abnormalities; babies whose } \\
\text { mothers are critically ill; } \\
\text { parental refusal. }\end{array}$ & $\begin{array}{l}\text { KMC }(n=63): \text { KMC duration at least } 6 \text { hours } \\
\text { per day in not more than } 4 \text { sittings, each } \\
\text { sitting lasting at least } 1 \text { hour. Mothers wore } \\
\text { a loose blouse covering the infant's trunk } \\
\text { and extremities but not the head, with the } \\
\text { baby was held upright between the breasts } \\
\text { and supported by } 3-\text { meter long flannel } \\
\text { clothes. Babies wore only diaper and a cap } \\
\text { during the period of KMC. Infants requiring } \\
\text { phototherapy were withdrawn from the } \\
\text { group and reintroduced afterwards. } \\
\text { Control }(n=63): \text { Babies were adequately } \\
\text { clothed, covered and kept with their mother. } \\
\text { If they did not maintain temperature, they } \\
\text { were kept under radiant warmer. }\end{array}$ & $\begin{array}{l}\text { - Medically stable } \\
\text { upon entry into } \\
\text { study. } \\
\text { - Birth weight: } \\
1385.87 \pm 234.12 \\
\text { g for KMC group } \\
\text { vs } 1458.57 \pm \\
172.66 \mathrm{~g} \text { for CMC } \\
\text { group ( } \mathrm{p}=0.05 \text { ) } \\
\text { - Weight at } \\
\text { recruitment: } \\
1458.57 \pm 172.66 \\
\text { g for KMC group, } \\
1385.87 \pm 234.12 \mathrm{~g} \\
\text { for CMC group. }\end{array}$ & $\begin{array}{l}\text { - Average weight gain } \\
\text { - Head circumference } \\
\text { - Length } \\
\text { - Hypothermia } \\
\text { - Apnea } \\
\text { - Duration of hospital } \\
\text { stay }\end{array}$ \\
\hline $\begin{array}{l}\text { Baton, } 2017 \\
\text { Single-center } \\
\text { RCT } \\
(n=32)\end{array}$ & $\begin{array}{l}\text { Inclusion: All preterm neonates } \\
\text { aged } 28 \text { to } 36 \text { weeks, weighing } \\
600 \text { to } 2000 \text { g, admitted at } \\
\text { the NICU, requiring intubation } \\
\text { and mechanical ventilation } \\
\text { due to respiratory distress, } \\
\text { but with stable heart rate, } \\
\mathrm{BP} \text { within normal range for } \\
\text { weight and age of gestation, } \\
\text { oxygen saturation }>90 \% \\
\text { and no adverse respiratory } \\
\text { events requiring emergent } \\
\text { interventions during the } \\
\text { previous } 12 \text { hours. } \\
\text { Exclusion: Age <28 weeks and } \\
\text { birthweight <600g; presence } \\
\text { of severe respiratory distress } \\
\text { (FiO }>50 \% \text { ), persistent } \\
\text { pulmonary hypertension, } \\
\text { intraventricular hemorrhage } \\
\geq \text { grade } 3 \text {, shock state as seen } \\
\text { in severe sepsis, and major } \\
\text { congenital abnormalities. }\end{array}$ & $\begin{array}{l}\text { KMC }(n=16): \text { KMC was provided to all } \\
\text { preterm neonates as soon as the infant } \\
\text { demonstrated stable vital signs while on the } \\
\text { ventilator. The infant and parent were kept } \\
\text { on the KMC position intermittently for } 2 \text { to } 4 \\
\text { hours daily, until they were extubated. } \\
\text { Control }(n=16): \text { The participants were } \\
\text { provided care inside an incubator. } \\
\text { All preterm neonates in both groups were } \\
\text { managed similarly except for the KMC } \\
\text { position in the intervention group. Since } \\
\text { KMC is the standard of care for all preterm } \\
\text { and low birthweight neonates in the study } \\
\text { facility, all neonates in both groups were } \\
\text { enrolled to the KMC program as soon as } \\
\text { they were extubated. }\end{array}$ & $\begin{array}{l}\text { - Mechanically } \\
\text { ventilated by } \\
\text { medically stable. } \\
\text { - No statistically } \\
\text { significant } \\
\text { difference between } \\
\text { the two groups in } \\
\text { terms of pregnancy, } \\
\text { maternal, and } \\
\text { infant demographic } \\
\text { characteristics. }\end{array}$ & $\begin{array}{l}\text { - Mortality rate } \\
\text { - Morbidity (sepsis, } \\
\text { pneumonia, } \\
\text { necrotizing } \\
\text { enterocolitis, } \\
\text { hypothermia) } \\
\text { - Number of days } \\
\text { intubated } \\
\text { - Duration of } \\
\text { hospitalization }\end{array}$ \\
\hline $\begin{array}{l}\text { Cattaneo, } \\
1998 \\
\text { Multicenter } \\
\text { RCT } \\
(\mathrm{n}=285)\end{array}$ & $\begin{array}{l}\text { Inclusion: Infants with birth } \\
\text { weight between } 1000 \\
\text { and } 1999 \mathrm{~g}, \text { regardless of } \\
\text { gestational age, without } \\
\text { oxygen and/or IV fluid } \\
\text { requirement, free of any visible } \\
\text { major malformation, able to } \\
\text { feed, and mother is present } \\
\text { and willing to collaborate } \\
\text { Exclusion: None stated }\end{array}$ & $\begin{array}{l}\text { KMC }(n=149) \text { : Continuous skin-to-skin } \\
\text { contact between mother's breasts, with } \\
\text { diaper and a hat with their mother's } \\
\text { clothes, for an average of about } 20 \\
\text { hours/d, even during mother's sleep. KMC } \\
\text { assistant replaces mothers on occasion } \\
\text { Control }(n=136) \text { : Infants were kept in a warm } \\
\text { room, with open cribs and the possibility } \\
\text { of rewarming in a bulb-heated cot, and in } \\
\text { incubators in the other } 2 \text { hospitals. }\end{array}$ & $\begin{array}{l}\text { - Medically stable } \\
\text { upon entry into } \\
\text { study. } \\
\text { - Infants <32 weeks } \\
\text { GA: } 24(16 \%) \text { for } \\
\text { KMC group vs } 14 \\
\text { (10\%) for CMC } \\
\text { group ( } p=0.02) \\
\text { - Breastfeeding at } \\
\text { hospital admission: } \\
63(48 \%) \text { for KMC } \\
\text { group vs } 49(40 \%) \\
\text { for CMC group } \\
\text { ( } p=0.001) \\
\text { Breastfeeding at } \\
\text { study enrollment: } \\
100(67 \%) \text { for KMC } \\
\text { group vs } 75(55 \%) \\
\text { for CMC group } \\
\text { (p = 0.003) }\end{array}$ & $\begin{array}{l}\text { - Severe illness } \\
\text { - Hypothermia } \\
\text { - Hyperthermia } \\
\text { - Breastfeeding } \\
\text { - Weight gain } \\
\text { - Neonatal death } \\
\text { - Acceptability to } \\
\text { health workers } \\
\text { - Acceptability } \\
\text { - to mothers } \\
\text { - Costs }\end{array}$ \\
\hline
\end{tabular}


Table 2. Characteristics of Included Studies Comparing KMC and Conventional Care on Premature, LBW Infants (continued)

\begin{tabular}{|c|c|c|c|c|}
\hline $\begin{array}{l}\text { Study, Year, } \\
\text { and Design (n) }\end{array}$ & $\begin{array}{c}\text { Inclusion and } \\
\text { Exclusion Criteria }\end{array}$ & Study Groups & $\begin{array}{l}\text { Description of Infants } \\
\text { Included in the Study }\end{array}$ & $\begin{array}{l}\text { Outcomes } \\
\text { Measured }\end{array}$ \\
\hline $\begin{array}{l}\text { Charpak, } \\
1997 \\
\text { Single-center } \\
\text { RCT } \\
(n=709)\end{array}$ & $\begin{array}{l}\text { Inclusion: Infants with } \\
\text { birth weights } \leq 2000 \mathrm{~g} \\
\text { born to mothers who } \\
\text { consented to participating } \\
\text { in the study and understand } \\
\text { protocol instructions. } \\
\text { Exclusion: Refusal to comply } \\
\text { with specifics of the } \\
\text { instructions (for KMC group), } \\
\text { referral to another institution, } \\
\text { plans to leave Bogotá in the } \\
\text { near future, life-threatening }\end{array}$ & $\begin{array}{l}\text { KMC }(n=396 \text { randomized, } 364 \text { analyzed } \\
\text { for mortality, } 343 \text { analyzed for hospital } \\
\text { length of stay): Firm skin-to-skin contact } \\
\text { to mother's chest was maintained } 24 \\
\text { hours a day with infants in a strict } \\
\text { upright position. Breastfeeding was done } \\
\text { regularly; premature formula supplements } \\
\text { were administered if necessary. } \\
\text { Control ( } n=381 \text { randomized, } 345 \text { analyzed } \\
\text { for mortality, } 320 \text { analyzed for hospital } \\
\text { length of stay): Infants were kept in an } \\
\text { incubator until they were able to regulate }\end{array}$ & $\begin{array}{l}\text { - Medically stable } \\
\text { upon entry into } \\
\text { study. } \\
\text { - No statistically } \\
\text { significant } \\
\text { difference between } \\
\text { the two groups in } \\
\text { terms of pregnancy, } \\
\text { maternal, and } \\
\text { infant demographic } \\
\text { characteristics. }\end{array}$ & $\begin{array}{l}\text { - Mortality } \\
\text { - Infant growth } \\
\text { - Length of hospital } \\
\text { stay } \\
\text { - Infection } \\
\text { - Breastfeeding } \\
\text { - Mother-infant } \\
\text { - } \text { attachment } \\
\text { - Neurodevelopmental } \\
\text { disability, and } \\
\text { social and home } \\
\text { environment }\end{array}$ \\
\hline
\end{tabular}
or major malformations, early temperature and were thriving. Parents' detected major conditions access to them was severely restricted. arising from perinatal problems, parental or family refusal to comply with the follow-up program

\begin{tabular}{|c|c|c|c|c|}
\hline $\begin{array}{l}\text { Charpak, } \\
2001 \\
\text { Single-center } \\
\text { RCT } \\
(\mathrm{n}=663)\end{array}$ & $\begin{array}{l}\text { Inclusion: Regardless of actual } \\
\text { weight or gestational age, } \\
\text { infants became eligible as } \\
\text { soon as they overcame major } \\
\text { problems of adaptation to } \\
\text { extrauterine life, had any } \\
\text { infection or concomitant } \\
\text { condition treated properly, } \\
\text { started sucking and } \\
\text { swallowing properly, and } \\
\text { had daily weight changes } \\
\text { appropriate for gestational } \\
\text { and chronological age. } \\
\text { Exclusion: Referral of infants to } \\
\text { another institution, parent/s } \\
\text { with plans to leave Bogotá in } \\
\text { the near future, lethal or major } \\
\text { malformations, early conditions } \\
\text { arising from perinatal problems } \\
\text { (e.g., severe hypoxic ischemic } \\
\text { encephalopathy, pulmonary } \\
\text { hypertension), and parental } \\
\text { or family refusal to comply } \\
\text { with the follow-up program or } \\
\text { with the (KMC) intervention. }\end{array}$ & $\begin{array}{l}K M C(n=339) \text { : Infants were kept in an } \\
\text { upright position, in skin-to-skin contact, } \\
\text { firmly attached to the mother's chest } \\
\text { for } 24 \text { hours a day. They were breastfed } \\
\text { regularly; premature formula supplements } \\
\text { were likewise given if necessary, to } \\
\text { guarantee adequate weight gain. They } \\
\text { were examined daily until they had a } \\
\text { weight gain of at least } 20 \mathrm{~g} / \text { day. } \\
\text { Control }(n=324) \text { : Infants were kept in } \\
\text { incubators until they could regulate their } \\
\text { temperature and showed appropriate weight } \\
\text { gain. While the infants were in the neonatal } \\
\text { care unit, their parents' access to them was } \\
\text { severely restricted. They were discharged } \\
\text { when they weight approximately } 1700 \mathrm{~g} \text {. }\end{array}$ & $\begin{array}{l}\text { - Medically stable } \\
\text { upon entry into } \\
\text { study. } \\
\text { - Compared to CMC } \\
\text { infants, KMC } \\
\text { infants weighed } \\
\text { significantly lighter } \\
\text { at time of eligibility } \\
(1678 \pm 226 \mathrm{~g} \\
\text { vs } 1715 \pm 228 \mathrm{~g} ; \\
\mathrm{p}=0.01) \text { and at } \\
\text { discharge from } \\
\text { their respective } \\
\text { treatment arms } \\
(1685 \pm 216 \mathrm{~g} \\
\text { vs } 1756 \pm 190 \mathrm{~g} ; \\
\mathrm{p}=0.01) .\end{array}$ & $\begin{array}{l}\text { - Morbidity } \\
\text { - Mortality } \\
\text { - Growth } \\
\text { - Development } \\
\text { - Breastfeeding } \\
\text { - Hospital stay } \\
\text { - Sequelae at } 12 \\
\text { months of corrected } \\
\text { age (cerebral palsy, } \\
\text { psychomotor delay, } \\
\text { visual or hearing } \\
\text { impairment) }\end{array}$ \\
\hline $\begin{array}{l}\text { Fortifaes, } \\
2017 \\
\text { Single-center } \\
\text { RCT } \\
(n=100)\end{array}$ & $\begin{array}{l}\text { Inclusion: Birthweight } 1500- \\
2500 \text { g; APGAR score }>5 \\
\text { at } 1 \text { minute of life; placed } \\
\text { on NIPPV; physiologically } \\
\text { stable (no desaturations, } \\
\text { apnea, bradycardia, } \\
\text { tachycardia, hypothermia, } \\
\text { hyperthermia, cyanosis) } \\
\text { Exclusion: Presence of cardiac } \\
\text { or surgical conditions; } \\
\text { permanent neurologic } \\
\text { abnormality affecting } \\
\text { respiration (e.g., hydrocephalus, } \\
\text { intraventricular hemorrhage, } \\
\text { nerve injury); multiple } \\
\text { congenital abnormalities }\end{array}$ & $\begin{array}{l}K M C(n=50) \text { : Infants were placed in } \\
\text { the kangaroo position on a parent } \\
\text { intermittently for a minimum of } 1 \text { hour } \\
\text { to maximum of } 4 \text { hours per session, to } \\
\text { be done } 3 \text { to } 4 \text { times a day every day } \\
\text { until they were weaned from NIPPV } \\
\text { Control }(n=50) \text { : Infants wore a cap } \\
\text { and diaper while placed in a bassinet. } \\
\text { Thermoregulation was done using a } \\
\text { droplight or application of plastic wraps } \\
\text { as necessary. }\end{array}$ & $\begin{array}{l}\text { - Medically stable } \\
\text { on NIPPV. } \\
\text { - The baseline } \\
\text { maternal } \\
\text { and neonatal } \\
\text { characteristics } \\
\text { were comparable } \\
\text { on both groups. }\end{array}$ & $\begin{array}{l}\text { - Physiologic } \\
\text { parameters (heart } \\
\text { rate, respiratory rate, } \\
\text { oxygen saturation, } \\
\text { temperature) } \\
\text { - Hospital length } \\
\text { of stay } \\
\text { - Adverse events } \\
\text { (hypothermia, } \\
\text { hyperthermia, } \\
\text { feeding difficulty, } \\
\text { seizures, skin color } \\
\text { changes) } \\
\text { - Mortality }\end{array}$ \\
\hline
\end{tabular}


Table 2. Characteristics of Included Studies Comparing KMC and Conventional Care on Premature, LBW Infants (continued)

\begin{tabular}{|c|c|c|c|c|}
\hline $\begin{array}{l}\text { Study, Year, } \\
\text { and Design (n) }\end{array}$ & $\begin{array}{c}\text { Inclusion and } \\
\text { Exclusion Criteria }\end{array}$ & Study Groups & $\begin{array}{l}\text { Description of Infants } \\
\text { Included in the Study }\end{array}$ & $\begin{array}{l}\text { Outcomes } \\
\text { Measured }\end{array}$ \\
\hline $\begin{array}{l}\text { Kadam, } 2005 \\
\text { Single-center } \\
\text { RCT } \\
(\mathrm{n}=89)\end{array}$ & $\begin{array}{l}\text { Inclusion: Infants with birth } \\
\text { weight }<1800 \text { g, stable } \\
\text { cardiopulmonary status, } \\
\text { Apgar score } \geq 7 \text { at } 5 \text { minutes, } \\
\text { and on feeds (breastfeeding } \\
\text { or spoon feeding of } \\
\text { expressed breast milk) } \\
\text { Exclusion: Sick and unstable } \\
\text { infants; presence of major } \\
\text { congenital malformations; } \\
\text { refusal of parents to consent }\end{array}$ & $\begin{array}{l}\text { KMC }(n=44) \text { : Infants kept in skin-to- } \\
\text { skin contact between mother's breasts } \\
\text { (minimum of } 1 \text { hour at a stretch, continued } \\
\text { for as long as comfortable), in vertical } \\
\text { position supported by dupatta cloth, with } \\
\text { mothers seating in a semi-reclining position. } \\
\text { Crossover to conventional care allowed } \\
\text { in case of any problems that arose; infant } \\
\text { transferred back to the KMC group after } \\
\text { stabilization, and treatment continued } \\
\text { thereafter until discharge. }\end{array}$ & $\begin{array}{l}\text { - Medically stable } \\
\text { upon entry into } \\
\text { study. } \\
\text { - No statistically } \\
\text { significant } \\
\text { difference between } \\
\text { the two groups in } \\
\text { terms of baseline } \\
\text { characteristics. }\end{array}$ & $\begin{array}{l}\text { - Mortality } \\
\text { - Hypothermia } \\
\text { - Hyperthermia } \\
\text { - Sepsis } \\
\text { - Apnea } \\
\text { - Onset of } \\
\text { breastfeeding } \\
\text { - Duration of hospital } \\
\text { - } \text { stay }\end{array}$ \\
\hline
\end{tabular}

Control $(n=45)$ : Infants kept in radiant warmers

Handling of babies, diaper changes, and breastfeeding by mothers were allowed at any hour of the day in both groups.

\section{Kambarami, Inclusion: Preterms $<7$ days 1998 old, birth weight <1600 g,}

Single-center RCT (n = 74) able to suck; mothers willing to participate in the study. Singletons only.

Exclusion: Twin births, presence of major congenital anomalies, recovery from major illness
$K M C(n=37)$ : Infants, wearing only a nappy, in skin-to-skin contact between mother's breasts in an upright position. A cover was put around mother and infant. $\mathrm{KMC}$ was carried out in a 12-bed KMC unit. All infants were entirely breastfed. Control $(n=37)$ : Infants were placed in incubators and received standard care. They were fed either formula or breast milk, or both. When incubators were overcrowded, some infants in this group were moved onto cots to make room for sicker infants requiring incubators. They were then returned to the incubators as soon as they became available again.
- Medically stable upon entry into study.

- Median weight study entry: $1460 \mathrm{~g}$ (range 1400-1545 g) for $\mathrm{KMC}$ group vs $1400 \mathrm{~g}$ (range $1260-1450 \mathrm{~g})$ for CMC group $(\mathrm{p}=0.004)$

- Median age on study entry: 5 days (range 4-7 days) for KMC group vs 3 days (range 1-6 days) for $\mathrm{CMC}$ group $(p=0.002)$

Luistro, 2014 Inclusion: Preterm neonates Single-center (<36 weeks) admitted at RCT $(n=70)$ unit weighing 1000-2000

- Infants requiring the neonatal intensive care $\mathrm{g}$, with Apgar score $>7$ at the first and fifth minute of life and requiring RAM cannula CPAP support due to respiratory distress. Exclusion: Babies with major congenital abnormalities, especially facial and gastrointestinal anomalies. Pediatric aging below 28 weeks and birth weight $<1000 \mathrm{~g}$ were likewise excluded.
$K M C(n=35): K M C$ was done to all participants starting at 24 hours of life intermittently for 4 hours daily until they are discharged.

Control $(n=35)$ : The participants in the control group were donned with a cap and diaper, were placed inside an incubator and were given conventional care.

\begin{tabular}{ll}
\hline Mwendwa, & Inclusion: Medically stable \\
2012 & LBW infants with birth \\
Single-center & weights of 1000-1750 g \\
RCT & Exclusion: None stated \\
$(\mathrm{n}=166)$ &
\end{tabular}

KMC $(n=85):$ KMC was practiced over an 8-hour period per day Control $(n=81)$ : Infants remained in incubators or cots

Mothers in both groups were encouraged to breastfeed, or feed expressed breast milk to their babies. Supplementation with infant formula was used when mothers were not producing enough breast milk. RAM cannula CPAP support due to respiratory distress upon entry into study

- Proportion of obstetric comorbidities: 16 (45.71\%) with KMC group vs 8 (22.86\%) with $\mathrm{CMC}$ group $(p=0.04)$

- Apgar score at 1 minute: $8.83 \pm 0.51$ for KMC group vs $8.37 \pm 1.19$ for $\mathrm{CMC}$ group $(\mathrm{p}=0.04)$

- Length of RAM cannula CPAP use

- Length of oxygen support

- Morbidity

- Mortality

- Sepsis

- Length of hospital stay

- Medically stable upon entry into study.

- Median maternal age: 26 years (range 17-34 years) for KMC group vs 24.5 years (range 15-33 years) for $\mathrm{CMC}$ group $(p=0.04)$.
- Weight

- Head circumference

- Mid-upper arm circumference

- Major illness

- Duration of stay gain

intercurrent illness in aspital

hospital stay

- Survival 
Table 2. Characteristics of Included Studies Comparing KMC and Conventional Care on Premature, LBW Infants (continued)

\begin{tabular}{|c|c|}
\hline $\begin{array}{l}\text { Study, Year, } \\
\text { and Design (n) }\end{array}$ & $\begin{array}{c}\text { Inclusion and } \\
\text { Exclusion Criteria }\end{array}$ \\
\hline $\begin{array}{l}\text { Rao, } 2008 \\
\text { Single-center } \\
\text { RCT } \\
(n=206)\end{array}$ & $\begin{array}{l}\text { Inclusion: Singleton infants wit } \\
\text { birth weight <2000 g } \\
\text { Exclusion: Critical illness in } \\
\text { infant, requiring ventilatory } \\
\text { or inotropic support; } \\
\text { presence of chromosomal } \\
\text { and life-threatening } \\
\text { congenital anomalies; infants } \\
\text { requiring transfer, or whose } \\
\text { mothers were critically ill } \\
\text { or unable to comply with } \\
\text { the follow-up schedule }\end{array}$ \\
\hline
\end{tabular}

Study Groups
KMC $(n=108)$ : Infants kept in skin-to-skin
contact in semi-upright position using a
"kangaroo bag" made of soft flannel cloth.
Mothers were encouraged to keep infant
in this position as long as possible during
the day and night, for a minimum period of
1 to 2 hours at a time. When not in KMC,
infants were placed under a servo-controlled
radiant warmer or in a cradle under a hot
lamp, clothed and covered.
Control ( $n=112):$ Infants were placed
under a servo-controlled radiant warmer
or in a cradle under a hot lamp in the
NICU adequately clothed and covered.

\section{Description of Infants Included in the Study}

- Medically stable upon entry into study.

- Age at enrollment: $3.7 \pm 2.8$ days for KMC group vs 2.3 \pm 1.9 days for CMC group ( $p<0.01$ )

- Weight at enrollment: 1607.6 \pm 278 for KMC group vs 1690.5 $\pm 273 \mathrm{~g}$, for CMC group ( $p=0.03$ )

- Gestational age: $35.3 \pm 2.3$ weeks for KMC group vs $35.9 \pm 2.1$ weeks for CMC group ( $\mathrm{p}=0.05)$

\begin{tabular}{ll}
\hline Rojas, 2003 & Inclusion: Hemodynamically \\
Single-center & stable infants with birth weight \\
$\mathrm{RCT}$ & $<1501 \mathrm{~g}$, gestational age $\leq 32$ \\
$(\mathrm{n}=60)$ & weeks, with minimal ventilatory \\
& support or extubated on nasal \\
& CPAP or nasal cannula \\
& Exclusion: Maternal age $<18$ \\
& years, maternal history of illicit \\
& drug use during pregnancy, \\
& clinical evidence of perinatal \\
& asphyxia, potential transfer \\
& within the first month after \\
& birth, presence of major \\
& congenital abnormalities, \\
& planned adoption, Grade III or \\
& IV intraventricular hemorrhage, \\
& fetal growth restriction, or \\
& suspected sepsis
\end{tabular}

Sloan, $1994 \quad$ Inclusion: Singleton infants Single-center $\overline{\text { weighing }}<2000 \mathrm{~g}$ with RCT acceptable food tolerance; ( $n=300) \quad$ no serious congenital abnormalities; no respiratory, metabolic, or infectious disease. Infants' temperature had to be stabilized between $36.5^{\circ} \mathrm{C}$ and $37.0^{\circ} \mathrm{C}$ for 24 hours before enrollment. Exclusion: None stated
KMC ( $n=33)$ : Infants (who wore only a diaper, with their backs were covered with a blanket) were held in a prone semiupright position at approximately a $45^{\circ}$ angle, in direct skin-to-skin contact with the parent's chest.

Control $(n=27)$ : Infants in this group received conventional care. Parents were allowed to remove them from the incubator and held them in their arms in supine position with eye-to-eye contact. Infants wore diapers and T-shirts and were wrapped in a blanket.
- Medically stable upon entry into study.

- No statistically significant difference between the two groups in terms of baseline characteristics.

\begin{tabular}{ll} 
KMC $(n=140)$ : Infants were kept in an & - Medically stable \\
\hline upright position, in skin-to-skin contact & upon entry into \\
against the mother's breasts and were & study. \\
frequently breastfed. Infants were allowed to & $\begin{array}{l}\text { No statistically } \\
\text { wear diaper. }\end{array}$ \\
Control $(n=160):$ Infants were kept in & difference between \\
incubators or thermal cribs and were & the two groups in \\
breastfed at scheduled times & terms of baseline \\
& characteristics.
\end{tabular}

characteristics.
- Weight gain

- Head circumference growth Breastfeeding

- Length of hospital stay

- Mortality

- Occurrence of sepsis, necrotizing enterocolitis, intraventricular hemorrhage
- Gain in weight, length, head, circumference, and foot length

Duration of hospital stay
- Illness severity (severe: lower respiratory tract disorder, apnea, aspiration, pneumonia, septicemia, general infection; moderate: urinary tract infection; mild: upper respiratory tract disorder, dermatitis, jaundice, hip displacement)

- Diarrhea

- Weight gain, length gain, upper arm and head circumference gain

- Post-eligibility mortality

- Hospital length of stay (only the difference between groups reported)

- Re-admission, Costs of care 
Table 2. Characteristics of Included Studies Comparing KMC and Conventional Care on Premature, LBW Infants (continued)

\begin{tabular}{|c|c|c|c|c|}
\hline $\begin{array}{l}\text { Study, Year, } \\
\text { and Design (n) }\end{array}$ & $\begin{array}{c}\text { Inclusion and } \\
\text { Exclusion Criteria }\end{array}$ & Study Groups & $\begin{array}{l}\text { Description of Infants } \\
\text { Included in the Study }\end{array}$ & $\begin{array}{l}\text { Outcomes } \\
\text { Measured }\end{array}$ \\
\hline $\begin{array}{l}\text { Tessier, } 2003 \\
\text { Single-center } \\
\text { RCT } \\
(n=336)\end{array}$ & $\begin{array}{l}\text { Inclusion: Birth weight } \\
<2000 \mathrm{~g}, \text { mother or relative } \\
\text { understand and willing } \\
\text { to follow instructions } \\
\text { Exclusion: Infant referred } \\
\text { to another institution, had } \\
\text { lethal or major malformations, } \\
\text { had sequelae from perinatal } \\
\text { problems, abandoned or given } \\
\text { up for adoption }\end{array}$ & $\begin{array}{l}\text { KMC }(n=183) \text { : Infants were maintained } \\
\text { in kangaroo position continuously, } \\
24 \text { hours a day, until they manifest } \\
\text { behaviorally that they are ready to be } \\
\text { separated, usually around } 37-38 \text { weeks } \\
\text { of gestational age. Other carers (i.e., the } \\
\text { father and grandmother) were allowed } \\
\text { to alternate with the mother in providing } \\
\text { skin-to-skin contact. Besides breastmilk, } \\
\text { infants may receive preterm formula and } \\
\text { vitamin supplements when necessary } \\
\text { Control ( } n=153) \text { : Infants were kept in } \\
\text { incubators until they could self-regulate } \\
\text { their temperature and had appropriate } \\
\text { weight gain. Mothers were encouraged to } \\
\text { breastfeed their infants as soon as possible. }\end{array}$ & $\begin{array}{l}\text { - Medically stable } \\
\text { upon entry into } \\
\text { study. } \\
\text { - No statistically } \\
\text { significant } \\
\text { difference between } \\
\text { the two groups in } \\
\text { terms of baseline } \\
\text { characteristics. }\end{array}$ & $\begin{array}{l}\text { - This study is part of } \\
\text { the RCT by Charpak } \\
\text { et al. (1997). Besides } \\
\text { outcomes measured } \\
\text { for that particular } \\
\text { RCT, developmental } \\
\text { scores (Griffiths) at } \\
12 \text { months were } \\
\text { likewise measured. }\end{array}$ \\
\hline $\begin{array}{l}\text { Whitelaw, } \\
1988 \\
\text { Single-center } \\
\text { RCT } \\
(\mathrm{n}=71)\end{array}$ & $\begin{array}{l}\text { Inclusion: Infants with birth } \\
\text { weight }<1500 \text { g, having stable } \\
\text { breathing with no oxygen } \\
\text { requirement, and with } \geq 1 \\
\text { parent speaking fluent English. } \\
\text { Exclusion: Presence of } \\
\text { congenital malformations (e.g., } \\
\text { hydronephrosis or scoliosis), } \\
\text { or intracranial lesions (e.g., } \\
\text { periventricular leukomalacia, } \\
\text { ventricular dilatation) }\end{array}$ & $\begin{array}{l}\text { KMC }(n=35) \text { : Infants were kept in an upright } \\
\text { position, in skin-to-skin contact between } \\
\text { the mother's breasts, with a cardiac or } \\
\text { respiration monitor attached. } \\
\text { Control }(n=36) \text { : Mother was encouraged } \\
\text { to visit as much as she liked and } \\
\text { helped to take her baby out of the } \\
\text { incubator for a cuddle. However, baby } \\
\text { and mother remained clothed. }\end{array}$ & $\begin{array}{l}\text { - Medically stable } \\
\text { upon entry into } \\
\text { study. } \\
\text { - No statistically } \\
\text { significant } \\
\text { difference between } \\
\text { the two groups in } \\
\text { terms of maternal } \\
\text { and infant baseline } \\
\text { characteristics. }\end{array}$ & $\begin{array}{l}\text { - Breastfeeding } \\
\text { - Infant's behavior at } 6 \\
\text { months of age (hours } \\
\text { sleeping, feeding, } \\
\text { being held, playing } \\
\text { per day, minutes } \\
\text { crying per day) } \\
\text { - Mother's feelings } \\
\text { about the infant at } \\
\text { discharge and at } \\
6 \text { months of age }\end{array}$ \\
\hline $\begin{array}{l}\text { Worku, } 2005 \\
\text { Single-center } \\
\text { RCT } \\
(n=165)\end{array}$ & $\begin{array}{l}\text { Inclusion: Birth weight <2000 g; } \\
\text { singletons only, unless } 1 \text { of the } \\
\text { twins died; no major congenital } \\
\text { malformations; mother healthy } \\
\text { and willing to participate } \\
\text { Exclusion: None stated }\end{array}$ & $\begin{array}{l}\text { KMC }(n=62) \text { : Continuous skin-to-skin } \\
\text { contact between mother and infant } \\
\text { starting during the first } 24 \text { hours of life. } \\
\text { The mother kept her newborn infant } \\
\text { between the breasts, in close contact with } \\
\text { her body and covered with her clothes } \\
\text { day and night. Breastfeeding was the } \\
\text { standard feeding method, but the mother } \\
\text { can also feed her baby with formula } \\
\text { milk using tube or cup when needed. } \\
\text { Control ( } n=61): \text { Routine care offered in the } \\
\text { neonatal unit to LBW infants, which included } \\
\text { an artificial warming system (heated room } \\
\text { overhead lamp warmers), oxygen therapy, } \\
\text { breast, tube, cup, or mixed feeding. }\end{array}$ & $\begin{array}{l}\text { - Medically unstable } \\
\text { infants allowed } \\
\text { to be recruited } \\
\text { into the study. } \\
\text { - The demographic } \\
\text { and socioeconomic } \\
\text { characteristics for } \\
\text { both groups are } \\
\text { comparable. }\end{array}$ & $\begin{array}{l}\text { - Death } \\
\text { - Serious illness } \\
\text { (sepsis, diarrhea, } \\
\text { pneumonia, } \\
\text { aspiration, } \\
\text { pneumonia) } \\
\text { - Mothers' feeling } \\
\text { about the } \\
\text { method of care }\end{array}$ \\
\hline
\end{tabular}

(Acharya, Cattaneo, Sloan, and Worku). Random allocation was carried out in 7 RCTs using brown, numbered, or sealed envelopes (Baton, Fortifaes, Kadam, Luistro, Rao, Rojas, and Whitelaw), while block randomization was done in the RCTs by Charpak, Tessier, and in the Yogyakarta arm of the multi-country RCT by Cattaneo. On the other hand, Kambarami et al. openly stated in their study that their infants were allocated consecutively without any concealment. Since consecutive allocation invariably does not reflect any randomization, there is a substantial risk that the resultant comparator groups would be significantly heterogeneous in terms of both measured and unmeasured confounders. In Mwendwa's study, details on the method of allocation were not explicitly described and only mentioned randomization to each group.

\section{Blinding (performance bias and detection bias)}

Due to the nature of the intervention (KMC), patient blinding is not possible in all the included studies. Furthermore, blinding of the assessor was not done in the 4 included studies. In the remaining 12 studies, it was not explicitly mentioned whether the assessors were blinded or not.

\section{Incomplete outcome data (attrition bias)}

The outcomes of interest were ascertained in all infants in most of the included studies, except for Rao et al. and Tessier et al. The former reported losses to follow-up of 11 and 38 in the $\mathrm{KMC}$ and control groups, respectively. Comparably, with Tessier et al., 32 and 30 infants (KMC and control groups, respectively) were pulled out from the study by their mothers. For both of these studies, reasons 
for these losses/dropouts were not disclosed, with these losses/dropouts likely to influence the final results.

On the other hand, Worku reported in their study that $91 \%$ and $88 \%$ of babies in the KMC and control groups, respectively, were discharged from the study during the first 7 days of life. It is unclear, however, whether the total number of infants used to compute the percentage for each group excluded the mortalities or not. It was likewise not explicitly mentioned if any outcome was ascertained with the remaining $9 \%$ of the infants in the KMC group and the remaining $12 \%$ in the control group.

\section{Selective reporting (reporting bias)}

Although Worku intended and designed their study as an RCT to compare the effectiveness of KMC compared to conventional care, it was unclear what parameters they based effectiveness on. Similarly, outcomes of interest were not clearly defined in their methodology, with infant mortality as the only outcome reported per study group in the results. For that matter, we assess this study to have a substantial risk of selective reporting bias.

For all other studies, their outcomes of interest were pre-specified and comprehensively reported in their results. Only the studies by Charpak et al. $(1997,2001)$ performed an intention-to-treat analysis.

\section{Other potential sources of bias}

Studies that were deemed to have an unclear risk for other biases are those that either had significant differences in baseline characteristics between-participant study groups (Acharya, Charpak [2001], Cattaneo, Kambarami, Luistro, and Rao reported significant differences in birthweight between study groups) or failed to include key baseline characteristics that may be associated with the outcomes of interest (Kadam did not include maternal baseline characteristics); and those that either did not provide statistical bases for their sample sizes (Acharya, Cattaneo, Kadam, Kambarami, Mwendwa, Rojas, Sloan, Tessier, and Worku) or had sample sizes that were found to have underpowered their respective studies on posthoc power analysis (Rojas and Sloan).

\section{Publication bias (Figure 3)}

On visual inspection, the funnel plot appears symmetrical; albeit intuitive and subjective, this indicates an absence of publication bias. The Egger test, which regresses the included studies' standardized effect sizes on their standard errors, was performed additionally to objectively assess for any publication bias. It tests the null hypothesis that no small-study effects (i.e., no indications of publication bias) are present. Yielding a $p$-value of 0.868 , the Egger test showed no substantial evidence to claim that publication bias exists among the studies included in this review.

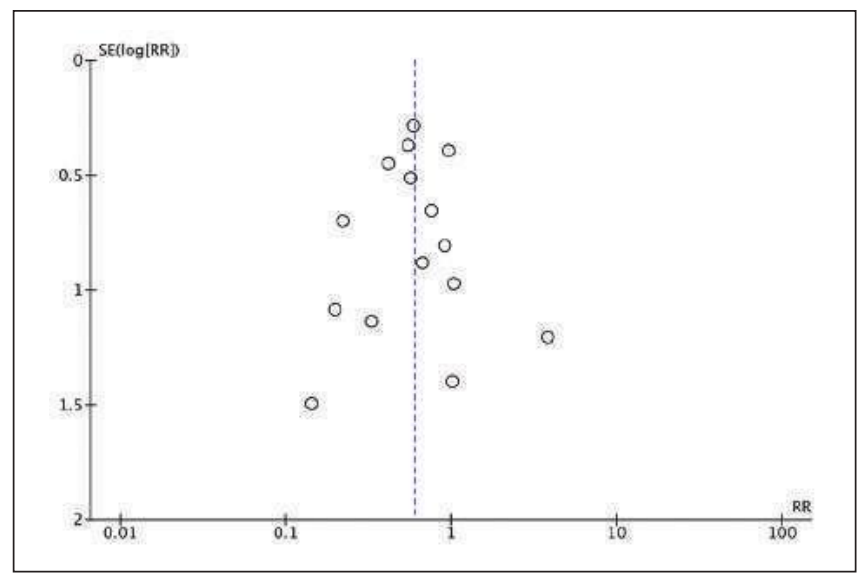

Figure 3. Funnel plot for studies reporting mortality.

\section{Effects of interventions}

\section{Primary Outcome: In-hospital mortality}

There was a significant reduction in the risk of dying by $41 \%$ among infants to whom KMC was rendered, compared with control $(3.86 \% \%$ vs $6.87 \%$; $\mathrm{RR}=0.59,95 \%$ CI 0.44 , $0.79 ; \mathrm{I}^{2}=0 \%$; number needed to treat for additional benefit $(\mathrm{NNTB})=34 ; 16$ RCTs; 3,412 infants). Of note, Acharya did not have any mortalities in both groups because no sick babies were included at the beginning of the study (Figure 4).

\section{Income category of the country of birth}

In a subgroup analysis of in-hospital mortality based on the economic status or income category of the country of birth, only two studies were classified under the high-income country (HIC) subgroup. There was a low pooled sample of 131 and thus, the confidence interval of the diamond was wide and crossed the line of no significance (KMC: $5.88 \%$ vs CMC: $4.76 \% ; \mathrm{RR}=1.24,95 \%$ CI $0.28,5.42 ; \mathrm{I}^{2}=0 \%$; 2 RCTs; 131 infants). However, in RCTs carried out in low to middle income countries (LMIC), there was a significant reduction in mortality among infants on $\mathrm{KMC}$ compared with controls (3.77\% vs $6.95 \% ; \mathrm{RR}=0.57,95 \%$ CI $0.43,0.77 ; \mathrm{I}^{2}=0 \%$; $\mathrm{NNTB}=32 ; 14$ RCTs; 3281 infants). Again, Acharya did not have any mortalities for both groups so that there was no estimable measure of association for this study (Figure 5).

\section{Gestational age}

In the subgroup analysis on gestational age, only 15 RCTs were analyzed, since Kambarami's study did not have information on the AOG of the infants. For both groups, the estimates are consistently on the side favoring KMC. However, the $\geq 34$-week-AOG subgroup's pooled estimate did not reach statistical significance (KMC: $3.48 \%$ vs $\mathrm{CMC}$ : $5.34 \% ; \mathrm{RR}=0.7,95 \% \mathrm{CI} 0.43,1.13 ; \mathrm{I}^{2}=0 \%$; 5 RCTs; 1543 infants). Among infants < 34 weeks, there was a significant reduction in mortality among those who were provided $\mathrm{KMC}$ compared with control (KMC: $4.32 \%$ 
vs $\mathrm{CMC}: 8.17 \%, \mathrm{RR}=0.55,95 \% \mathrm{CI} 0.38,0.79 ; \mathrm{I}^{2}=0 \%$; $\mathrm{NNTB}=26 ; 10 \mathrm{RCTs} ; 1795$ infants) (Figure 5).

\section{Birth weight}

In the subgroup analysis on birth weight, a 40\% reduction in the risk of dying (KMC: $3.97 \%$ vs CMC: $6.83 \%, \mathrm{RR}=0.60 ; 95 \%$ CI $0.45,0.82 ; \mathrm{I}^{2}=0 \%$;NTB $=$ 35; 10 RCTs; 2960 infants) was demonstrated among infants belonging to the $\geq 1500 \mathrm{~g}$ subgroup who were provided KMC. Similarly, the pooled estimate for the $<1500 \mathrm{~g}$ subgroup was on the side favoring $\mathrm{KMC}$, but it did not reach statistical significance. Again, this could be due to the much smaller sample size of this subgroup $(n=452)$ compared with the bigger infants $(n=2960)$. If both subgroups had comparable sample sizes, they would most probably have the same point estimate (Figure 5).

\section{Medical stability}

Among infants who were medically stable, there was a significant reduction in the risk of dying by $38 \%$ among those receiving $\mathrm{KMC}$ (KMC: $2.98 \%$ vs $\mathrm{CMC}$ : $5.22 \%$; $\mathrm{RR}=0.62 ; 95 \%$ CI $0.43,0.89 ; \mathrm{I}^{2}=0 \%$;NTB $=45 ; 11$ RCTs; 3025 infants). Analysis was also done among infants assessed to be medically unstable (intubated [Baton]; requiring nasal CPAP [Luistro]; requiring NIPPV [Fortifaes]; on minimal ventilatory support, and if extubated, on $\mathrm{CPAP} / \mathrm{O}_{2}$ support [Rojas]; on oxygen or IV support [Worku]), which likewise showed a significant reduction in

\section{Mortality}

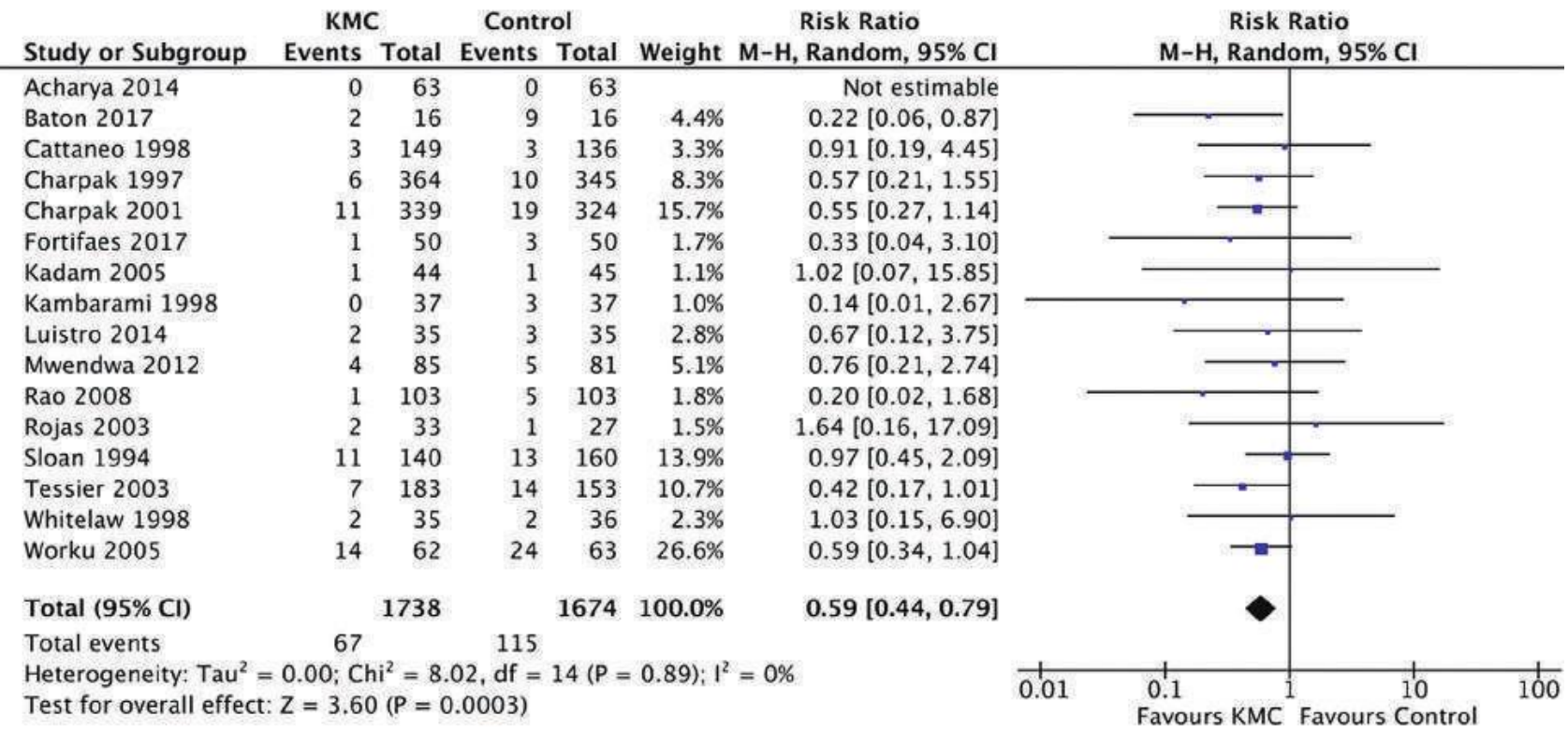

\section{Hospital Length of Stay}

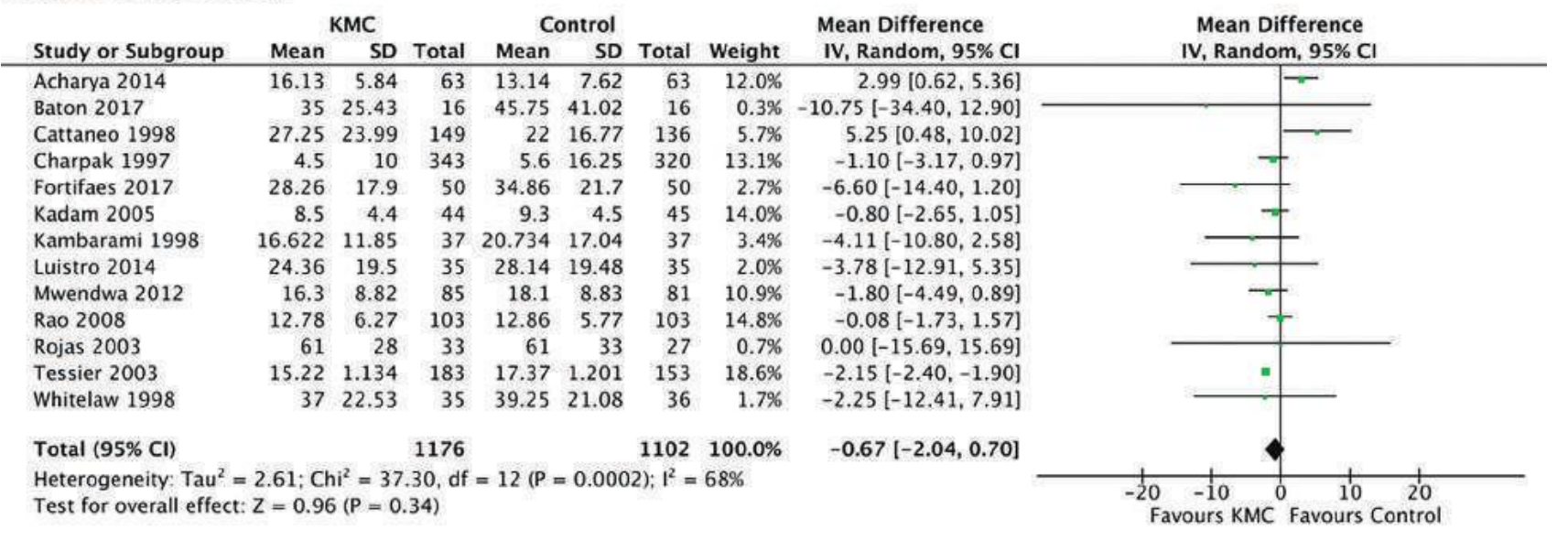

Figure 4. Forest plots for the outcomes of interest (infant mortality reported as risk ratios, and hospital length of stay reported as risk differences). 


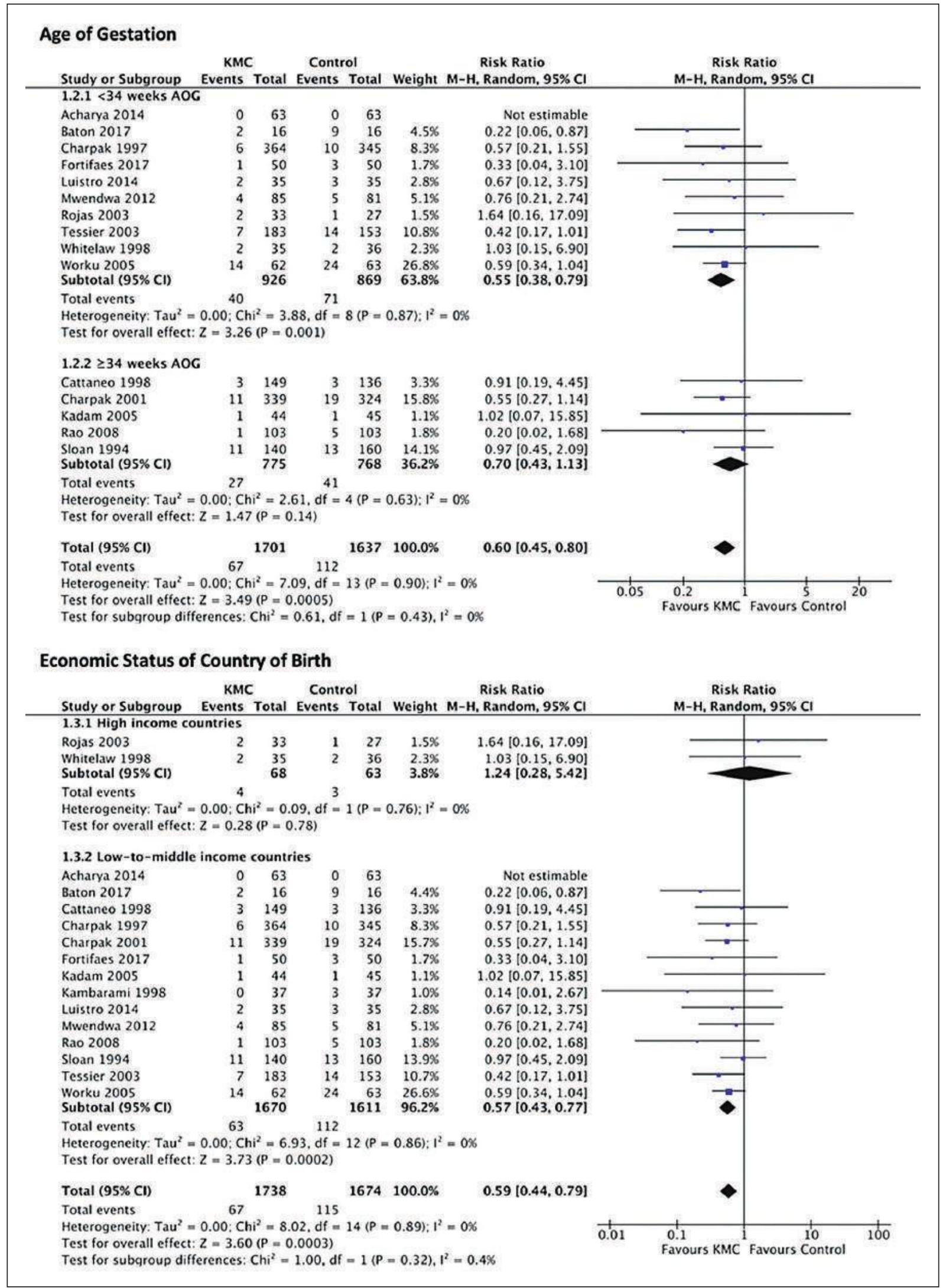

Figure 5. Forest plots for the subgroup analyses on infant mortality (age of gestation, economic status of country of birth, birthweight and medical stability). 


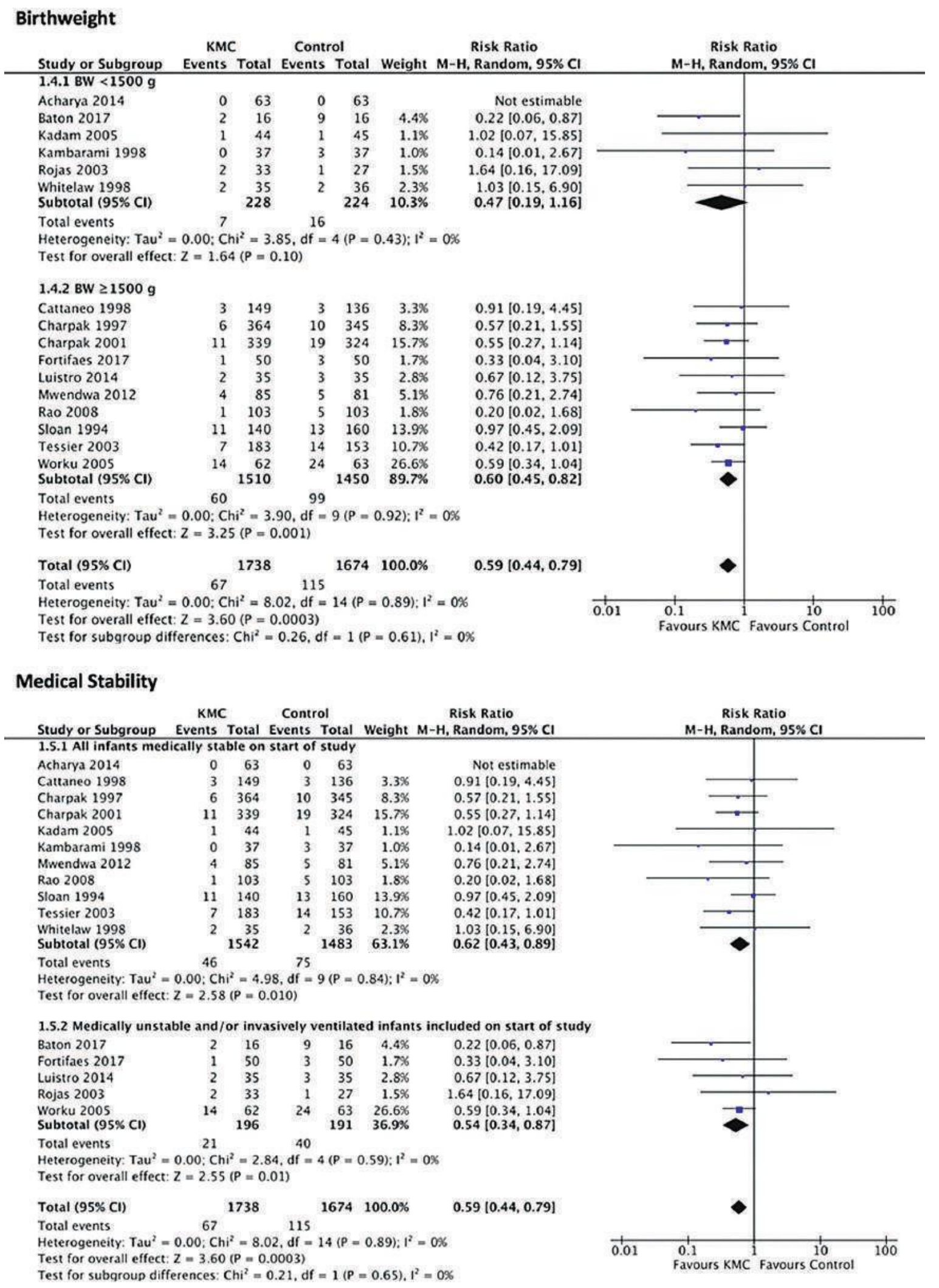

Figure 5. Forest plots for the subgroup analyses on infant mortality (age of gestation, economic status of country of birth, birthweight and medical stability). (continued) 
the risk of dying by $46 \%$ in favor of those rendered $\mathrm{KMC}$ compared with the control group (KMC: $11.05 \%$ vs CMC: $20.94 \% ; \mathrm{RR}=0.54 ; 95 \%$ CI $0.34,0.87 ; \mathrm{I}^{2}=0 \%$;NTB $=11$; 5 RCTs; 387 infants) (Figure 5).

\section{Secondary Outcome: Hospital Length of Stay}

Of the 16 studies included, only 13 had data on hospital length of stay (HLOS). Charpak (2001) did not report the mean and standard deviation of HLOS for each intervention group but instead reported the mean HLOS by birthweight classifications with age-corrected to term, 3, 6, and 9 months. The study of Samra reported NICU length of stay rather than the total HLOS. Sloan merely reported the mean difference of 2 days between intervention groups with a longer stay among those on $\mathrm{KMC}$, without providing information on means and standard deviations. Some of the studies included in this analysis reported median and range (Baton, Cattaneo, Kambarami, and Whitelaw). In such cases, the mean and standard deviation were estimated based on the method devised by Hozo, Djulbegovic, and Hozo. ${ }^{29}$

For studies that reported mean and range instead of standard deviation (Charpak, 1997), the standard deviation was estimated by using the formula: $(\max -\min ) / 4$. For studies that reported mean and interquartile range (IQR) instead of standard deviation (Kambarami), the standard deviation was estimated by using the formula: $\left(\mathrm{Q}_{3}-\right.$ $\left.\mathrm{Q}_{1}\right) / 1.35$. For studies that reported mean and sample size but no standard deviation (Tessier), the pooled standard deviation was computed instead. Overall, the pooled estimated did not reach statistical significance (mean difference: -0.67 ; 95\% CI $-2.04,0.70 ; p=0.34$ ). Of note, the $\mathrm{I}^{2}$ statistic is quite high (68\%), warranting subgroup analysis to explain this heterogeneity (Figure 4).

\section{Income category of country of birth}

The respective pooled estimates of infants born in HIC and LMIC did not reach statistical significance, although infants born in LMIC have a tendency towards benefit. However, the $\mathrm{I}^{2}$ in the LMIC subgroup is higher than the overall $\mathrm{I}^{2}$ at $68 \%$. Therefore, this particular subgroup analysis did not explain the heterogeneity between studies (Figure 6).

\section{Gestational age}

Kambarami did not have any information on the age of gestation. Thus, only 12 studies were included in this subgroup analysis. Point estimates of the pooled effects of the subgroups were divergent (one on each side of the null value of 0 ). The $<34$-week-AOG subgroup pooled estimate suggested a tendency towards benefit but was not statistically significant. Moreover, $\mathrm{I}^{2}$ values remained high, indicating that this subgroup analysis did not explain the heterogeneity from earlier (Figure 6).

\section{Birth weight}

The $\geq 1500-\mathrm{g}$ birth weight subgroup appeared to be at an advantage in terms of having shorter HLOS compared to the $<1500-g$ subgroup, though this was not statistically significant. Furthermore, this subgroup analysis did not explain the high $\mathrm{I}^{2}$ from the overall analysis on the effect of KMC on HLOS (Figure 6).

\section{Medical stability}

There was a tendency towards a shorter HLOS among medically unstable infants treated with KMC, though this was not statistically significant. Notable also was that the $\mathrm{I}^{2}$ was $0 \%$ for this subgroup. KMC could have a potential for a shorter HLOS among infants who were medically unstable upon NICU admission (Figure 6).

\section{RESULTS AND DISCUSSION}

Sixteen trials comparing the effect on in-hospital mortality of infants who were provided $\mathrm{KMC}$ versus control among 3,412 LBW or preterm infants showed a significant reduction in the risk of dying by $41 \%$. Similarly, the reduction in the risk of dying among those on KMC was $40 \%$ in the updated 2016 meta-analysis by CondeAgudelo $^{8}$ and $36 \%$ in the 2016 meta-analysis by Boundy. ${ }^{25}$ This meta-analysis showed a larger reduction in the risk of dying among KMC infants in low-to-middle income countries at $43 \%$, compared to $35 \%$ in the 2016 metaanalysis by Conde-Agudelo. This meta-analysis likewise included a set of subgroup analyses based on gestational age, showing a significant reduction in mortality among infants less than 34 weeks AOG. Of note as well, KMC infants with birthweight $\geq 1500 \mathrm{~g}$ had a significant reduction in mortality compared to lighter infants. This may be due to lighter infants having more preterm comorbidities compared with slightly heavier ones. An important finding in this review was the significant reduction in the risk of dying by $44 \%$ with a low number needed to treat at 11 .

KMC has been found to significantly reduce the risk of sepsis and hypothermia, as well as increase breastfeeding success. All these KMC benefits contribute to the overall reduction in neonatal mortality. However, despite the solid evidence shown by several studies on the benefits of KMC, uptake of the program is still far from ideal. Every Newborn Tracking Tool maps the coverage of four essential newborn care interventions, namely antenatal steroids, resuscitation, management of sepsis, and KMC. Sadly, only 11 out of 51 countries include $\mathrm{KMC}$ in their health management information system. ${ }^{30}$

Most notable in this meta-analysis was the reduction in the risk of dying when $\mathrm{KMC}$ is provided to medically unstable infants requiring respiratory support ranging from oxygen administration via nasal cannula to invasive positive pressure ventilation. As pointed out earlier, the number 


\section{Birthweight}

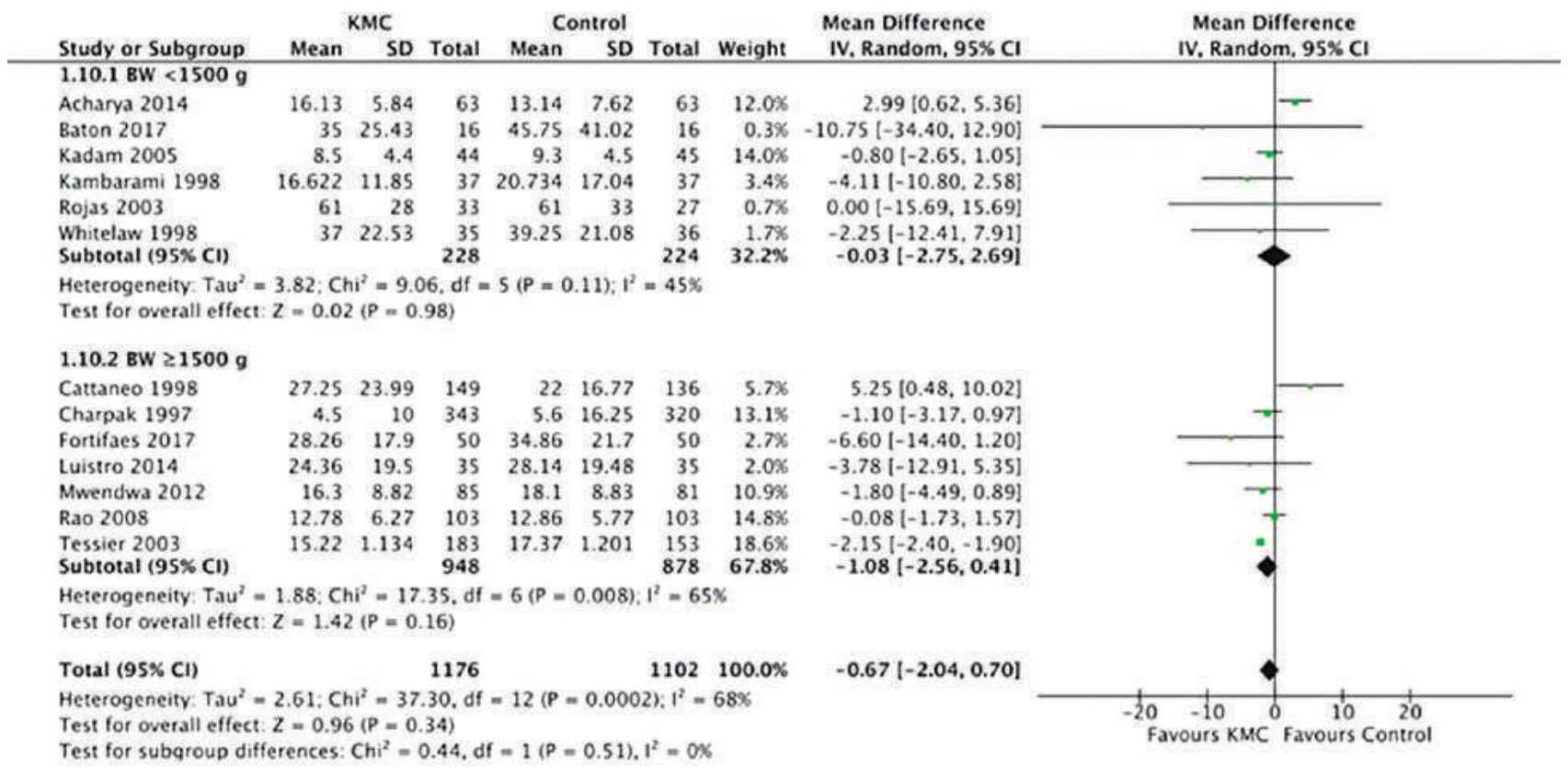

\section{Medical Stability}

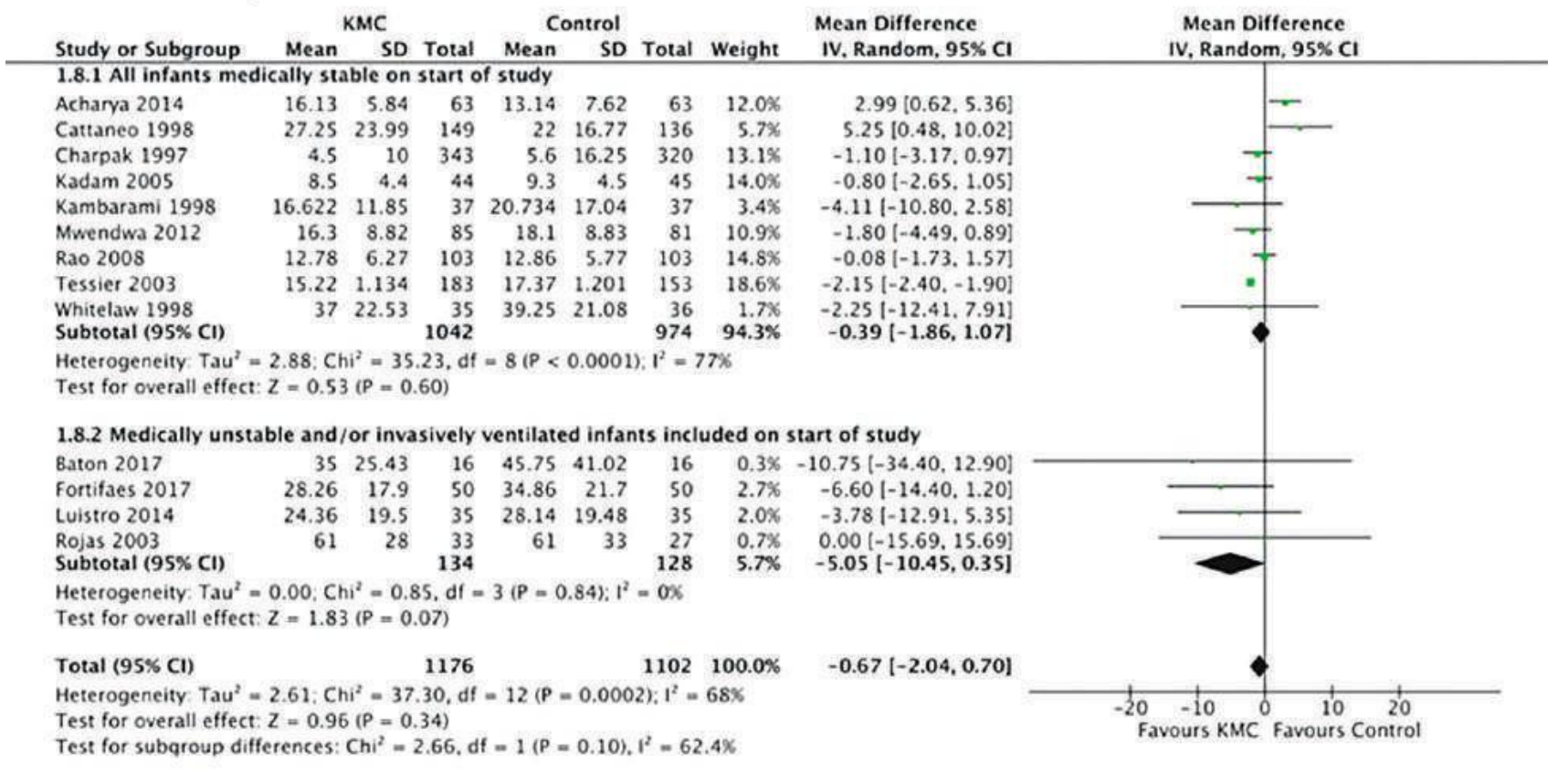

Figure 6. Forest plots for the subgroup analyses on hospital length of stay (age of gestation, economic status of country of birth, birthweight and medical stability).

needed to treat among these infants was the lowest in this review, at 11 . These findings should encourage better uptake of the KMC program not only among stable preterm or LBW infants but also among the sicker ones who could potentially benefit from this more. WHO recommends scaling up KMC programs, commencing at birth and continuing well into the period when the infant is already at home. This would mean an earlier start and a longer duration of KMC among infants who have respiratory distress at birth. In the study by Morgan et al., the mothers were agreeable to start the KMC in the first 24 hours. Other identified factors that are believed to significantly improve uptake 


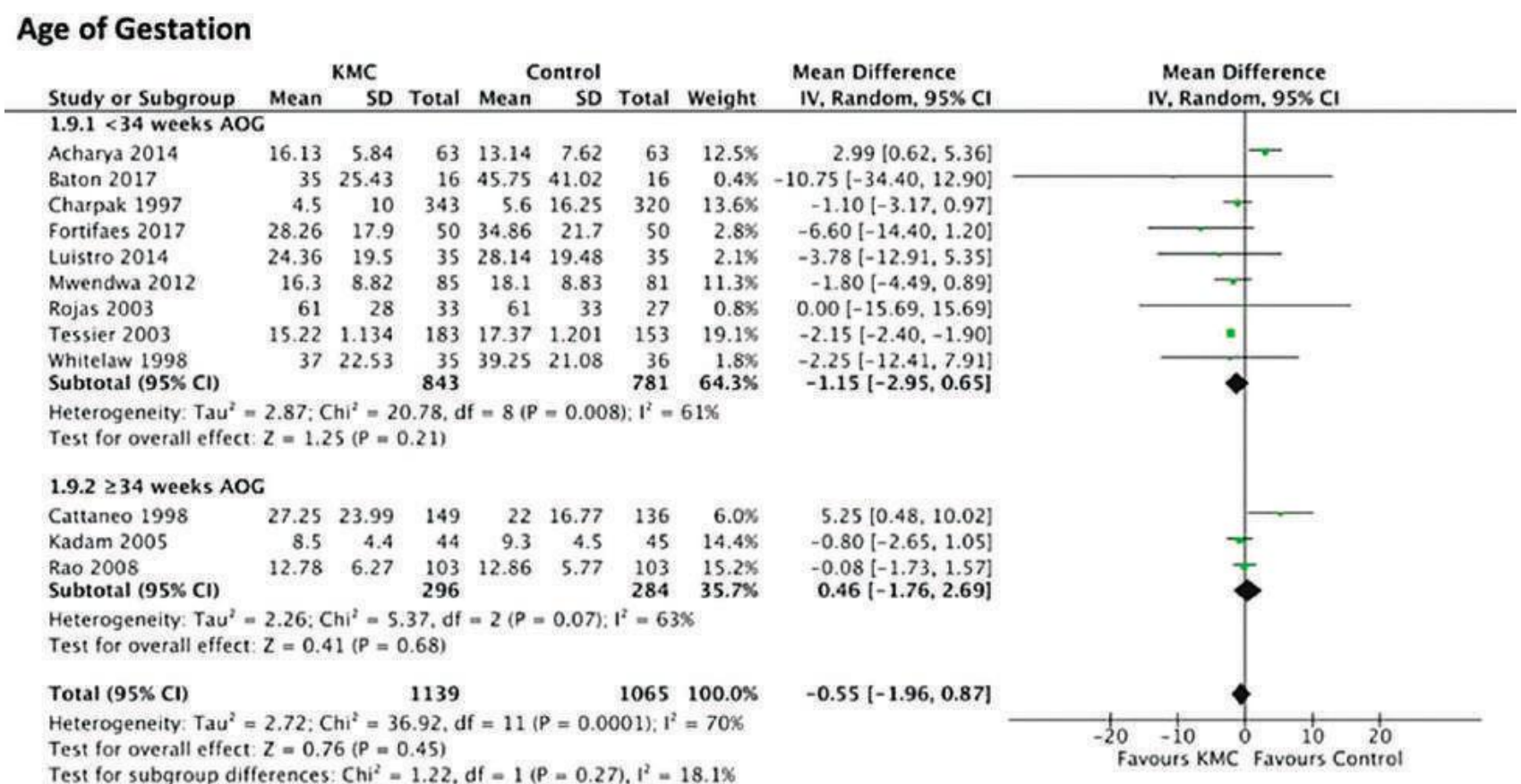

\section{Economic Status of Country of Birth}

\begin{tabular}{|c|c|c|c|c|c|c|c|}
\hline \multirow[b]{2}{*}{ Study or Subgroup } & \multicolumn{3}{|c|}{ KMC } & \multicolumn{3}{|c|}{ Control } & \multirow[b]{2}{*}{ Weight } \\
\hline & Mean & SD & Total & Mean & SD & Total & \\
\hline \multicolumn{8}{|l|}{$1.7 .1 \mathrm{HIC}$} \\
\hline Rojas 2003 & 61 & 28 & 33 & 61 & 33 & 27 & $0.7 x$ \\
\hline $\begin{array}{l}\text { Whitelaw } 1998 \\
\text { Subtotal }(95 \% \mathrm{CI})\end{array}$ & 37 & 22.53 & $\begin{array}{l}37 \\
70\end{array}$ & 39.25 & 21.08 & $\begin{array}{l}36 \\
63\end{array}$ & $\begin{array}{l}1.7 \% \\
2.4 \%\end{array}$ \\
\hline \multicolumn{8}{|c|}{$\begin{array}{l}\text { Heterogeneity: } \mathrm{Tau}^{2}=0.00 ; \mathrm{Chi}^{2}=0.06, \mathrm{df}=1(\mathrm{P}=0.81) ; \mathrm{I}^{2}=0 \mathrm{x} \\
\text { Test for overall effect: } \mathrm{Z}=0.37(\mathrm{P}=0.71)\end{array}$} \\
\hline \multicolumn{8}{|l|}{ 1.7.2 LMIC } \\
\hline Acharya 2014 & 16.13 & 5.84 & 63 & 13.14 & 7.62 & 63 & $12.0 \%$ \\
\hline Baton 2017 & 35 & 25.43 & 16 & 45.75 & 41.02 & 16 & $0.3 \%$ \\
\hline Cattaneo 1998 & 27.25 & 23.99 & 149 & 22 & 16.77 & 136 & $5.7 \%$ \\
\hline Charpak 1997 & 4.5 & 10 & 343 & 5.6 & 16.25 & 320 & $13.1 \%$ \\
\hline Fortifaes 2017 & 28.26 & 17.9 & 50 & 34.86 & 21.7 & so & $2.7 \%$ \\
\hline Kadam 2005 & 8.5 & 4.4 & 44 & 9.3 & 4.5 & 45 & $14.0 \mathrm{x}$ \\
\hline Kambarami 1998 & 16.622 & 11.85 & 37 & 20.734 & 17.04 & 37 & $3.4 \%$ \\
\hline Luistro 2014 & 24.36 & 19.5 & 35 & 28.14 & 19.48 & 35 & 2.08 \\
\hline Mwendwa 2012 & 16.3 & 8.82 & 85 & 18.1 & 8.83 & 81 & 10.98 \\
\hline Rao 2008 & 12.78 & 6.27 & 103 & 12.86 & 5.77 & 103 & $14.8 \%$ \\
\hline $\begin{array}{l}\text { Tessier } 2003 \\
\text { Subtotal }(95 \% \mathrm{CI})\end{array}$ & 15.22 & 1.134 & $\begin{array}{r}183 \\
1108\end{array}$ & 17.37 & 1.201 & $\begin{array}{r}153 \\
1039\end{array}$ & $\begin{array}{l}18.6 \% \\
97.6 \%\end{array}$ \\
\hline \multicolumn{8}{|c|}{$\begin{array}{l}\text { Heterogeneity } \mathrm{Tau}^{2}=2.84 ; \mathrm{Chi}^{2}=37.24, \mathrm{df}=10(\mathrm{P}<0.0001): \mathrm{I}^{2}=73 \% \\
\text { Test for overall effect: } \mathrm{Z}=0.89(\mathrm{P}=0.37)\end{array}$} \\
\hline Total $(95 \% \mathrm{Cl})$ & & & 1178 & & & 1102 & $100.0 \%$ \\
\hline \multicolumn{8}{|c|}{$\begin{array}{l}\text { Heterogeneity: } \text { Tau }^{2}=2.61 ; \mathrm{Chi}^{2}=37.30, \mathrm{df}=12(P=0.0002) ; \mathrm{I}^{2}=68 \% \\
\text { Test for overall effect: } Z=0.96(P=0.34)\end{array}$} \\
\hline
\end{tabular}

Mean Difference Mean Difference

$0.00[-15.69,15.69]$ $-2.25[-12.26,7.76]$ $-1.60[-10.04,6.84]$ IV, Random, $95 \% \mathrm{CI}$

Figure 6. Forest plots for the subgroup analyses on hospital length of stay (age of gestation, economic status of country of birth, birthweight and medical stability). (continued)

of the KMC program are improvement of the following: knowledge about KMC in the family and the community, staff counseling, infant monitoring, and family support. Conversely, barriers to universal KMC uptake that need to be overcome are: stigmatization of preterm birth, poor infant monitoring, lack of family support, finances and time away from work, lack of beds and spaces for $\mathrm{KMC}$ in the NICU, and lack of KMC education. ${ }^{26}$

In this meta-analysis, an assessment of the duration of hospitalization among infants provided $\mathrm{KMC}$ was performed. HLOS as an outcome measure was used as a surrogate to faster improvement or recovery from preterm 
or LBW complications, ultimately leading to better survival. Analysis of the pooled estimates showed no difference in the length of hospital stay between infants provided KMC and those who were not. A possible reason for this is that not all of the studies included in this review that report in-hospital mortality as outcomes likewise report HLOS. Per the criteria for studies to be included in this meta-analysis, the primary outcome is in-hospital mortality; data on length of hospital stay were extracted only from the already-included studies, even though there were more RCTs on KMC that were retrieved on an initial search that report length of hospital stay. Overall, only 13 out of the 16 included studies reported length of hospital stay. There were trends towards a shorter hospital stay among infants in the KMC group who were younger albeit heavier, unstable, and born in LMIC; these were the same subgroups found to have a significant reduction in in-hospital mortality in this metaanalysis. If studies that did not report in-hospital mortality but reported HLOS were allowed to be included in the analysis, this could have possibly led to pooled estimates that would demonstrate findings of a significant reduction in hospital stay in the $\mathrm{KMC}$ group. Another possible reason for the finding of no difference in the length of hospital stay between the KMC and the control groups might be that the infants in the control group who survived tended to be more stable, bigger, and physiologically more mature so that their hospital stay was generally shorter. On the other hand, the infants who survived in the KMC group were found to be younger (albeit relatively heavier) and more clinically unstable; such characteristics inadvertently translated to having a longer hospital course. A third possible reason was that since the majority of (medically unstable premature and LBW) infants would tend to die during the first week of life, ${ }^{3}$ a technically shorter length of hospital stay would be recorded. Since the control group overall reported more infant deaths compared to the $\mathrm{KMC}$ group, an overall shorter HLOS spuriously resulted.

\section{Overall completeness and applicability of evidence}

Besides the differences mentioned previously under the section of 'Other potential sources of bias,' the study participants in both treatment groups among the RCTs included generally had comparable baseline characteristics. All outcome measures were analyzed and presented. The results of this review applied to the different subgroups included in the trials.

\section{Quality of the evidence}

All the included studies, which were of the randomized controlled trial design, were individually appraised by two authors. Recommended methods of allocation concealment (i.e., block randomization, use of opaque brown envelopes, use of random number tables) were noted with the included studies, except for the RCT by Kambarami, which allocated their study participants via alternation. Due to the nature of the intervention (KMC), blinding was not possible. Although outcome assessors in the studies included were also not blinded, the outcomes of interest in this meta-analysis (in-hospital mortality and HLOS) were hard objective outcomes that are easy to ascertain.

The overall quality of evidence for outcomes in this review was considered moderate.

\section{Potential biases in the review process}

The eligibility and exclusion criteria in all RCTs were both specified. There was a systematic and comprehensive search strategy used in the identification and retrieval of pertinent studies included in this review. The authors reviewed the articles and extracted data independently. Any disparity was resolved through consensus.

\section{Agreements and disagreements with other studies or reviews}

This review added three local clinical trials. The magnitude of the reduction in mortality among the KMC infants found in this meta-analysis was similar to those seen in the reviews by Conde-Agudelo ${ }^{8}$ and Boundy. ${ }^{25}$ Similar to the meta-analysis by Conde-Agudelo, there was also a significant reduction in mortality among KMC infants in low-tomiddle income countries. In addition, this review analyzed the effect of KMC on mortality according to subgroups of gestational age and infant birth weight. Furthermore, this meta-analysis reported a significant reduction in the risk of dying among medically unstable infants.

\section{CONCLUSIONS}

\section{Implications for practice}

This review demonstrated that there was a significant reduction in mortality by $41 \%$ among infants who were rendered KMC. Furthermore, there was also a significant benefit of KMC among younger infants and those born in low-to-middle income countries. More importantly, this review demonstrated the medically unstable infants (i.e., requiring respiratory support) significantly benefitted from KMC.

\section{Implications for research}

Due to the findings of benefit among younger and medically unstable preterm infants, further studies on these subgroups of preterm and LBW infants should be undertaken. Assessment of the implementation of scaledup KMC programs that start from birth would further provide evidence of KMC's benefit. Additionally, long-term outcomes on neurologic development and catch-up growth would also be important to pursue.

\section{Statement of Authorship}

This meta-analysis was principally conceived by EVU and $\mathrm{MVH}$ as part of their requirement in their Masters' 
class. Both likewise conducted the search process. EVU excluded duplicate articles. EVU and MVH independently reviewed the full text of the remaining articles to determine their eligibility based on the set inclusion criteria. SLM was the third author to break the tie and resolve any disagreement. The PRISMA diagram was done by ESK.

\section{Author Disclosure}

All authors declared no conflicts of interest and no affiliation with any pharmaceutical company.

\section{Funding Source}

The authors did not receive funding for this study.

\section{REFERENCES}

1. UNICEF Data. Neonatal Mortality [Internet]. 2020 September. Available from: https://data.unicef.org/topic/child-survival/neonatalmortality/

2. WHO. Every Newborn 2025 Coverage Target \& Milestones Launch Sep3 2020, Moving faster to end preventable newborn deaths and stillbirths by 2030 [Internet]. 2020. [cited 2021 September]. Available from https://www.who.int/docs/defaultsource/mca-documents/nbh/enap-2025-targets/presentation-everynewborn-2025-coverage-target-milestones-launch-sep-3-2020. pdf?sfvrsn=7865286c_2

3. WHO. Newborns: improving survival and well-being [Internet]. 2020 Sept. [cited 2021 September]. Available from: https://www. who.int/news-room/fact-sheets/detail/newborns-reducing-mortality

4. UN Inter-agency Group for Child Mortality Estimation. Levels \& Trends in Child Mortality Report 2019 [Internet]. 2019. [cited 2021 September]. Available from: https://www.unicef.org/media/60561/ file/UN-IGME-child-mortality-report-2019.pdf

5. Hug L, Alexander M, You D, Alkema L. UN Inter-agency Group for Child Mortality Estimation. National, regional, and global levels and trends in neonatal mortality between 1990 and 2017, with scenariobased projections to 2030: a systematic analysis [published correction appears in Lancet Glob Health. 2019 Sep; 7(9): e1179]. Lancet Glob Health. 2019; 7(6):e710-e720. doi:10.1016/S2214-109X (19)30163-9

6. Furman L. Kangaroo mother care 20 years later: connecting infants and families. Pediatrics. 2017; 139(1): e20163332

7. Kangaroo mother care to reduce morbidity and mortality in low-birthweight infants [Internet]. 11 February 2019. [cited 2021 September]. Available from: https://www.who.int/elena/titles/kangaroo_care_ infants/en/

8. Conde-Agudelo A, Díaz-Rossello JL. Kangaroo mother care to reduce morbidity and mortality in low birth weight infants. Cochrane Database Syst Rev. 2016 Aug 23; 2016(8): CD002771. doi: 10.1002/14651858.CD002771.pub4.

9. Chan GJ, Valsangkar B, Kajeepeta S, Boundy EO, Wall S. What is kangaroo mother care? Systematic review of the literature. J Glob Health. 2016 Jun; 6(1):010701. doi: 10.7189/jogh.06.010701.

10. Ibe OE, Austin T, Sullivan K, Fabanwo O, Disu E, Costello AM. A comparison of kangaroo mother care and conventional incubator care for thermal regulation of infants $<2000 \mathrm{~g}$ in Nigeria using continuous ambulatory temperature monitoring. Ann Trop Paediatr. 2004;24(3):245-251. doi:10.1179/027249304225019082

11. Mank A, van Zanten HA, Meyer MP, Pauws S, Lopriore E, Te Pas $\mathrm{AB}$. Hypothermia in preterm infants in the first hours after birth: occurrence, course and risk factors. PLoS One. 2016 Nov 3;11(11): e0164817. doi: 10.1371/journal.pone.0164817.

12. Pavlyshyn H, Sarapuk I, Casper C, Makieieva N. Kangaroo mother care can improve the short-term outcomes of very preterm infants. J Neonatal Perinatal Med. 2021; 14(1):21-28. doi: 10.3233/NPM200455 .
13. Ghojazadeh M, Hajebrahimi S, Pournaghi-Azar F, Mohseni M, Derakhshani N, Azami-Aghdash S. Effect of kangaroo mother care on successful breastfeeding: a systematic review and meta-analysis of randomised controlled trials. Rev Recent Clin Trials. 2019; 14(1): 31-40. doi: 10.2174/1574887113666180924165844.

14. Mekonnen AG, Yehualashet SS, Bayleyegn AD. The effects of kangaroo mother care on the time to breastfeeding initiation among preterm and LBW infants: a meta-analysis of published studies. Int Breastfeed J. 2019 Feb 19; 14:12. doi: 10.1186/s13006-019-0206-0.

15. Parsa P, Karimi S, Basiri B, Roshanaei G. The effect of kangaroo mother care on physiological parameters of premature infants in Hamadan City, Iran. Pan Afr Med J. 2018 May 31; 30:89. doi: 10.11604/ pamj.2018.30.89.14428.

16. Sharma D, Murki S, Pratap OT. The effect of kangaroo ward care in comparison with "intermediate intensive care" on the growth velocity in preterm infant with birth weight <1100 g: randomized control trial. Eur J Pediatr. 2016 Oct;175(10):1317-24. doi: 10.1007/s00431016-2766-y.

17. Mörelius E, Örtenstrand A, Theodorsson E, Frostell A. A randomised trial of continuous skin-to-skin contact after preterm birth and the effects on salivary cortisol, parental stress, depression, and breastfeeding. Early Hum Dev. 2015 Jan; 91(1):63-70. doi: 10.1016/j.earlhumdev.2014.12.005.

18. Xie X, Chen X, Sun P, Cao A, Zhuang Y, Xiong X, Yang C. Kangaroo mother care reduces noninvasive ventilation and total oxygen support duration in extremely low birth weight infants. Am J Perinatol. 2021 Jul; 38(8):791-5. doi: 10.1055/s-0039-3402717.

19. Silva MG, Barros MC, Pessoa ÚM, Guinsburg R. Kangaroo-mother care method and neurobehavior of preterm infants. Early Hum Dev. 2016 Apr; 95:55-9. doi: 10.1016/j.earlhumdev.2016.02.004.

20. Charpak N, Tessier R, Ruiz JG, Hernandez JT, Uriza F, Villegas J, Nadeau L, Mercier C, Maheu F, Marin J, Cortes D, Gallego JM, Maldonado D. Twenty-year Follow-up of kangaroo mother care versus traditional care. Pediatrics. 2017 Jan; 139(1):e20162063. doi: 10.1542/peds.2016-2063.

21. Mazumder S, Upadhyay RP, Hill Z, Taneja S, Dube B, Kaur J, Shekhar M, Ghosh R, Bisht S, Martines JC, Bahl R, Sommerfelt H, Bhandari N. Kangaroo mother care: using formative research to design an acceptable community intervention. BMC Public Health. 2018 Mar 2; 18(1):307. doi: 10.1186/s12889-018-5197-z.

22. Joshi M, Sahoo T, Thukral A, Joshi P, Sethi A, Agarwal R. Improving duration of kangaroo mother care in a tertiary-care neonatal unit: a quality improvement initiative. Indian Pediatr. 2018 Sep 15; 55(9):744-7.

23. Weldearegay HG, Medhanyie AA, Abrha MW, Tadesse L, Tekle E, Yakob B, Girma T, Arsenault C. Quality of kangaroo mother care services in Ethiopia: implications for policy and practice. PLoS One. 2019 Nov 22; 14(11):e0225258. doi: 10.1371/journal.pone.0225258.

24. Chan G, Bergelson I, Smith ER, Skotnes T, Wall S. Barriers and enablers of kangaroo mother care implementation from a health systems perspective: a systematic review. Health Policy Plan. 2017 Dec 1; 32(10):1466-75. doi: 10.1093/heapol/czx098.

25. Boundy EO, Dastjerdi R, Spiegelman D, Fawzi WW, Missmer SA, Lieberman E, Kajeepeta S, Wall S, Chan GJ. Kangaroo mother care and neonatal outcomes: a meta-analysis. Pediatrics. 2016 Jan; 137(1):e20152238. doi: 10.1542/peds.2015-2238.

26. Morgan MC, Nambuya H, Waiswa P, Tann C, Elbourne D, Seeley J, Allen E, Lawn JE. Kangaroo mother care for clinically unstable neonates weighing $\leq 2000 \mathrm{~g}$ : Is it feasible at a hospital in Uganda? J Glob Health. 2018 Jun; 8(1):010701. doi: 10.7189/jogh.08.010701.

27. Higgins JPT, Green S, editors. Cochrane Handbook for Systematic Reviews of Interventions. Version 5.1.0. The Cochrane Collaboration 2011; [Internet]. Updated March 2011. Available from: https:// handbook-5-1.cochrane.org/Vol.

28. Schünemann H, Broek J, Guyatt G, Oxman A (editors). GRADE Handbook [Internet]. Updated October 2013. [cited 2021 September]. Available from: https://gdt.gradepro.org/app/handbook/handbook. html 
29. Hozo SP, Djulbegovic B, Hozo I. Estimating the mean and variance from the median, range, and the size of a sample. BMC Med Res Methodol. 2005 Apr 20; 5:13. doi: 10.1186/1471-2288-5-13.

30. WHO, Reaching the Every Newborn National 2020 Milestones [Internet]. 2017. [cited 2021 September]. Available from: http:// apps.who.int/iris/bitstream/handle/10665/255719/9789241512619eng.pdf;jsessionid=120FF4F69A12EB31031CC31C90FF2D31? sequence $=1$

\section{Included Studies}

1. Acharya N, Singh RR, Bhatta NK, Poudel P. Randomized controlled trial of kangaroo mother care in low-birth-weight babies at a tertiary level hospital. J Nepal Paediatr Soc. 2014; 34(1):18-23.

2. Baton SM, Uy MEV, Mendoza SL. Effectiveness of kangaroo mother care in decreasing neonatal mortality among intubated preterm neonates 28 to 36 weeks gestational age, weighing 600 to 2000 grams at birth: a randomized controlled trial. (in press)

3. Cattaneo A, Davanzo R, Worku B, Surjono A, Echeverria M, Bedri A, et al. Kangaroo mother care for low birth weight infants: a randomized controlled trial in different settings. Acta Paediatr. 1998 Sep; 87(9):976-85. doi: 10.1080/080352598750031653.

4. Charpak N, Ruiz-Peláez JG, Figueroa de C Z, Charpak Y. Kangaroo mother versus traditional care for newborn infants Pediatrics. 1997; 100(4):682-8. doi:10.1542/peds.100.4.682

5. Charpak N, Ruiz-Pelaez JG, Figueroa de C Z, Charpak Y. A randomized, controlled trial of kangaroo mother care: results of follow-up at 1 year of corrected age. Pediatrics. 2001; 108(5):1072-9. doi:10.1542/peds.108.5.1072

6. Fortifaes MR. Effectiveness of kangaroo mother care $(\mathrm{kmc})$ among low birthweight newborns on nasal intermittent positive pressure ventilation (nippv) versus low birthweight newborns on nippv under open care system: a randomized controlled trial (in press)

7. Kadam S, Binoy S, Kanbur W, Mondkar JA, Fernandez A. Feasibility of kangaroo mother care in Mumbai. Indian J Pediatr. 2005; 72(1): 35-38. doi:10.1007/BF02760578

8. Kambarami RA, Chidede O, Kowo DT. Kangaroo care versus incubator care in the management of well preterm infants--a pilot study. Ann Trop Paediatr. 1998 Jun; 18(2):81-6. doi: 10.1080/02724 936.1998.11747932.
9. Luistro C, Uy MEV. Effectiveness of kangaroo care versus conventional care among preterm neonates aged less than 36 weeks weighing below and equal to 2000 grams on RAM cannula continuous positive airway pressure: a randomized controlled trial. In press

10. Mwendwa AC, Musoke RN, Wamalwa DC. Impact of partial kangaroo mother care on growth rates and duration of hospital stay of low-birth-weight infants at the Kenyatta National Hospital, NairobI. East Afr Med J. 2012 Feb; 89(2):53-8.

11. Suman RP, Udani R, Nanavati R. Kangaroo mother care for low-birthweight infants: a randomized controlled trial. Indian Pediatr. 2008 Jan; 45(1):17-23.

12. Rojas MA, Kaplan M, Quevedo M, Sherwonit E, Foster L, Ehrenkranz RA, Mayes L. Somatic growth of preterm infants during skin-toskin care versus traditional holding: a randomized, controlled trial. J Dev Behav Pediatr. 2003 Jun; 24(3):163-8. doi: 10.1097/00004703200306000-00006.

13. Sloan NL, Camacho LW, Rojas EP, Stern C. Kangaroo mother method: randomised controlled trial of an alternative method of care for stabilised low-birthweight infants. Maternidad Isidro Ayora Study Team. Lancet. 1994; 344(8925):782-5. doi:10.1016/ s0140-6736(94)92341-8

14. Tessier R, Cristo MB, Velez S, Giron M, Nadeau L, de Calume ZF, et al. Kangaroo Mother Care: A method for protecting high-risk low-birth-weight and premature infants against developmental delay. Infant Behavior and Development. 2003 Aug 1; 26(3):384-97.

15. Whitelaw A, Heisterkamp G, Sleath K, Acolet D, Richards M. Skin to skin contact for very low birth weight infants and their mothers. Arch Dis Child. 1988; 63(11):1377-81. doi:10.1136/adc. 63.11.1377

16. Worku B, Kassie A. Kangaroo mother care: a randomized controlled trial on effectiveness of early kangaroo mother care for the low birth weight infants in Addis Ababa, Ethiopia. J Trop Pediatr. 2005; 51(2):93-7. doi:10.1093/tropej/fmh085
Have you read the current trends in Medical and Health Research in the Philippines?

\section{Acta Medica Philippina The National Health Science Journal}

\author{
Access Online: www.actamedicaphilippina.upm.edu.ph
}

